\title{
Probiotics Improve Eating Disorders in Mandarin Fish (Siniperca chuatsi) Induced by a Pellet Feed Diet via Stimulating Immunity and Regulating Gut Microbiota
}

\author{
Xiaoli Chen ${ }^{1,2}$, Huadong $\mathrm{Yi}^{1,2}$, Shuang Liu ${ }^{1,2}$, Yong Zhang ${ }^{1}$, Yuqin Su ${ }^{1,2}$, Xuange Liu ${ }^{1,2}$, Sheng Bi ${ }^{1,2}$, Han Lai ${ }^{1,2}$, \\ Zeyu Zeng ${ }^{1,2}$ and Guifeng $\mathrm{Li}^{1,2, *}$ \\ 1 State Key Laboratory of Biocontrol, Guangdong Provincial Key Laboratory for Aquatic Economic Animals, \\ School of Life Sciences, Sun Yat-Sen University, Guangzhou 510275, China; \\ chenxli27@mail2.sysu.edu.cn (X.C.); yihd3@mail2.sysu.edu.cn (H.Y.); liush276@mail2.sysu.edu.cn (S.L.); \\ lsszy@mail.sysu.edu.cn (Y.Z.); suyq9@mail2.sysu.edu.cn (Y.S.); liuxg27@mail2.sysu.edu.cn (X.L.); \\ bish@mail2.sysu.edu.cn (S.B.); laih5@mail2.sysu.edu.cn (H.L.); zengzy5@mail3.sysu.edu.cn (Z.Z.) \\ 2 Guangdong Provincial Engineering Technology Research Center for Healthy Breeding of Important Economic \\ Fish, Guangzhou 510006, China \\ * Correspondence: liguif@mail.sysu.edu.cn
}

\section{check for} updates

Citation: Chen, X.; Yi, H.; Liu, S.; Zhang, Y.; Su, Y.; Liu, X.; Bi, S.; Lai, H.; Zeng, Z.; Li, G. Probiotics Improve Eating Disorders in Mandarin Fish (Siniperca chuatsi) Induced by a Pellet Feed Diet via Stimulating Immunity and Regulating Gut Microbiota. Microorganisms 2021, 9, 1288. https:// doi.org/10.3390/microorganisms9061288

Academic Editor:

Konstantinos Ar. Kormas

Received: 24 May 2021

Accepted: 9 June 2021

Published: 12 June 2021

Publisher's Note: MDPI stays neutral with regard to jurisdictional claims in published maps and institutional affiliations.

Copyright: (c) 2021 by the authors. Licensee MDPI, Basel, Switzerland. This article is an open access article distributed under the terms and conditions of the Creative Commons Attribution (CC BY) license (https:/ / creativecommons.org/licenses/by/ $4.0 /)$.

\begin{abstract}
Eating disorders are directly or indirectly influenced by gut microbiota and innate immunity. Probiotics have been shown to regulate gut microbiota and stimulate immunity in a variety of species. In this study, three kinds of probiotics, namely, Lactobacillus plantarum, Lactobacillus rhamnosus and Clostridium butyricum, were selected for the experiment. The results showed that the addition of three probiotics at a concentration of $10^{8}$ colony forming unit $/ \mathrm{mL}$ to the culture water significantly increased the ratio of the pellet feed recipients and survival rate of mandarin fish (Siniperca chuatsi) under pellet-feed feeding. In addition, the three kinds of probiotics reversed the decrease in serum lysozyme and immunoglobulin $\mathrm{M}$ content, the decrease in the activity of antioxidant enzymes glutathione and catalase and the decrease in the expression of the appetite-stimulating regulator agouti gene-related protein of mandarin fish caused by pellet-feed feeding. In terms of intestinal health, the three probiotics reduced the abundance of pathogenic bacteria Aeromonas in the gut microbiota and increased the height of intestinal villi and the thickness of foregut basement membrane of mandarin fish under pellet-feed feeding. In general, the addition of the three probiotics can significantly improve eating disorders of mandarin fish caused by pellet feeding.
\end{abstract}

Keywords: eating disorders; feeding behavior; gut microbiota; Siniperca chuatsi; innate immunity; appetite; Lactobacillus plantarum; Lactobacillus rhamnosus; Clostridium butyricum

\section{Introduction}

Eating disorders mainly refer to a group of syndromes characterized by abnormal feeding behaviors, accompanied by significant weight changes or physiological dysfunctions [1-3]. The main clinical types include anorexia nervosa, bulimia nervosa, binge eating disorder and avoidance/restrictive food intake disorder. Moreover, eating disorders occur throughout the age groups and have an essential impact on physical and mental health [4]. They increase the likelihood of anxiety, obesity, suicidal intentions, depression, drug abuse and health problems [5]. Eating disorders are associated with the establishment of food preferences and aversions and are influenced by the sensorial characteristics of food [6]. A better understanding of food preferences and aversions can improve the prevention and treatment of eating disorders [7].

Food preference is an innate behavioral trait which is affected by both genes and the environment [8,9]. The hypothalamus contains orexigenic neurons that express neuropeptide $\mathrm{Y}(\mathrm{NPY})$ and agouti-related peptide (AgRP), which participate in food intake control and are regulated by the peripheral hormone leptin and ghrelin $[10,11]$. NPY is a 
peptide composed of 36 amino acids. As an appetite-stimulating factor, it plays a crucial role in regulating energy homeostasis and food intake [12]. AgRP increases food intake by antagonizing the effect of the anorexigenic POMC product, $\alpha$-melanocyte stimulating hormone $(\alpha-\mathrm{MSH})[13,14]$. There seems to be a species-specific variability in the functions of leptin and ghrelin with regards to the regulation of feeding and metabolism in fish [15]. Ghrelin acts as an appetite stimulant in a variety of fish species, but there is also conflicting evidence, such as in Salmoniformes [16].

As an essential modulator of host physiology and behavior, intestinal bacteria have been shown to influence feeding behavior and food choice [17-25]. Gut microbiota can influence host eating behavior by directly affecting nutrient sensing, appetite and satietyregulating systems through the production of neuroactive substances and short-chain fatty acids or indirectly manipulating intestinal barrier function, interacting with bile acid metabolism, modulating the immune system and influencing host antigen production [26]. Gut microbiota play a vital role in regulating host eating disorders' behavioral comorbidities, such as obesity, anorexia nervosa and severe acute malnutrition. A growing body of evidence links the gut microbiota with nutrition, immune, anti-oxidative stress and appetite. Influencing one of these factors will most likely lead to changes in the others, thereby making the gut microbiota easily accessible and manipulable for targeting host food preferences [26].

Administration of probiotics is an effective strategy to maintain the balance of the gut microbiota [27]. Probiotics are defined as microbial cells or compounds that have a beneficial effect on the health of the host. In aquaculture, probiotics can prevent the spread of diseases, increase food conversion efficiency and stimulate growth by improving the composition of the gastrointestinal microbiota, strengthening the immune system and increasing the resistance to farmed stressors [28-30]. In addition, probiotics have become an alternative to antibiotics and other drug treatments in the aquaculture industry and are considered a new tool for disease control [28,31,32]. Microorganisms commonly used as probiotics in aquaculture include bacteria, yeast and algae [33].

Among several probiotic bacterial species, numerous reports have been published on the beneficial role of Lactobacillus plantarum, Lactobacillus rhamnosus and Clostridium butyricum as probiotics in aquaculture [34-40]. L. plantarum is a rod-shaped, gram-positive, non-spore-forming facultative anaerobic bacteria that belong to the Lactobacillaceae family. It has been reported to reduce the adhesion and growth of harmful bacteria via producing antimicrobial compounds [41-43], improve the growth and feed efficiency of carp (Catla catla) [44,45], grouper (Epinephelus coioides) [46], tilapia (Oreochromis niloticus) [47], shrimp (Penaeus indicus) [48] and pacific white shrimp (Litopenaeus vannamei) [49] and enhance the immunity and survival rate of pacific white shrimp (Litopenaeus vannamei) [50,51] and tilapia [52]. Previous studies have shown that L. rhamnose can affect the appetite and energy metabolism of the host by regulating the expression of $\gamma$-aminobutyric acid and its receptors in the central nervous system [53-57]. C. butyricum is a spore-forming bacterium belonging to Gram-positive anaerobe that can produce butyric acid and exists in the intestine of healthy animals and human [58-60]. Compared with other probiotics, C. butyricum has a more vital tolerance ability to higher temperature environments, lower $\mathrm{pH}$, bile salt and several antibiotics. Therefore, C. butyricum has always been regarded as a good and safe food additive [58]. C. butyricum has a positive effect on immune function and is connected with increased population of Bifidobacterium and Lactobacillus and decreased concentration of pathogenic bacteria in the intestinal tract of humans, mice, piglets and broiler chickens $[61,62]$. C. butyricum can inhibit intestinal inflammation and regulate gut microbiota through the immune pathway [63-65].

Mandarin fish (Siniperca chuatsi) is a precious freshwater farmed fish with unique live bait feeding habits, and it does not easily accept dead bait or pellet feed $[10,66]$. The preference for a live bait diet increases the cost of mandarin fish farming and the risk of infectious diseases, limiting the development of mandarin fish farming. For this problem, previous studies mainly focused on optimizing the domestication process and breeding 
conditions (such as temperature), strengthening the training of learning and memory and using attractants, which promoted the development of pellet feed for mandarin fish [67-70]. However, there are still problems such as high mortality and slow growth of mandarin fish fed with pellet feed. Recently, relationships among gut microbiota, host immunity and feeding preference behavior have attracted research attention [71]. Probiotics intervention is an effective way to regulate the gut microbiota [27]. In this study, three probiotics that have been shown to be safe for aquatic animals, L. plantarum, L. rhamnosus and C. butyricum, were selected to investigate whether probiotics can improve the eating disorders of mandarin fish caused by pellet feed diet by modulating the gut microbiota, immune parameters, appetite and intestinal morphology, which may contribute to the theoretical foundation of probiotics intervention in the treatment of dietary disorders.

\section{Materials and Methods}

\subsection{Bacteria Strains}

The three probiotic strains, L. plantarum (ATCC 8014), L. rhamnosus (ATCC 7469) and C. butyricum (ATCC 19398), were purchased from Guangdong Microbial Culture Collection Center (GDMCC). The bacteria were cultured as described previously [36,72,73]. Briefly, the two activated bacterial suspensions of L. plantarum and L. rhamnosus were separately incubated into MRS liquid broth (Merck, Darmstadt, Germany). The activated bacterial suspension of $C$. butyricum was incubated into the reinforced clostridial medium (RCM) and then placed in an anaerobic workstation at $37^{\circ} \mathrm{C}$ for $12 \mathrm{~h}$. The bacterial titers were measured by making tenfold dilution series in triplicate on agar plates. Optical densities (OD) were measured using a spectrophotometer (Spectroscan UV 2600, Thermo Scientific, Waltham, MA, USA) at $600 \mathrm{~nm}$. The strains were harvested via centrifugation at $4000 \times g$ for $10 \mathrm{~min}$, washed twice with normal saline $(0.9 \% \mathrm{NaCl})$ and resuspended at $2 \times 10^{10}$ colony forming unit (CFU)/mL in sterile normal saline. Culture bacterial cells were afterward kept at $4{ }^{\circ} \mathrm{C}$ until usage.

\subsection{Animal Treatments}

All experimental procedures were approved by the Institutional Animal Care and Use Committee of Sun Yat-sen University and performed according to the guidelines for experimental animals established by this committee. One thousand and five hundred healthy mandarin fish were obtained from a fish farm in Foshan, Guangdong, China. All experimental fish were acclimatized for two weeks in $3200 \mathrm{~L}$ rectangular aquaria to laboratory conditions before pellet-feed feeding.

After the adaptive feeding, a total of 1350 healthy mandarin fish weighing $2.5 \pm 0.1 \mathrm{~g}$ (mean \pm standard error of mean (SEM)) were randomly allocated into one of five groups (270 fish per group): live bait fish feeding group (LBFD), pellet-feed feeding group with probiotics free (PFD), pellet-feed feeding group with L. plantarum plus (PFDLP), pelletfeed feeding group with L. rhamnosus plus (PFDLR) and pellet-feed feeding group with C. butyricum plus (PFDCB). Each group of experimental fish was randomly assigned to three $800 \mathrm{~L}$ replicated water tanks (90 fish per tank). Mandarin fish in the PFDLP, PFDLR and PFDCB groups were treated with L. plantarum, L. plantarum and C. butyricum at a final concentration of $10^{8} \mathrm{CFU} / \mathrm{mL}$ for one week, while the remaining two groups, LBFD and PFD, were not treated. In this time, all fish received a live bait fish diet twice a day (at 06:00 and $18.00 \mathrm{~h}$ ) at $5 \%$ of initial body weight. Mud carp (Cirrhinus molitorella) was used as the live bait fish in this study.

During the period of pellet-feed feeding, the PFD, PFDCB, PFDLR and PFDLP groups of experimental fish were overfed from dead fish (1 week) to commercial feed (4 weeks) following the domestication process established by Liang et al. [67], while the LBFD group of experimental fish maintained a live bait diet. Each group of experimental fish was fed twice a day (at 06:00 and $18.00 \mathrm{~h}$ ) at 5\% of initial body weight to approximate satiation. The main nutritional composition of the commercial feed purchased from Foshan Nanhai Jieda Feed Co., LTD. (Lishui, China), is $48 \%$ crude protein, $5 \%$ crude fat, $3 \%$ crude fiber, 
$19 \%$ crude ash, $10 \%$ water, $4 \%$ calcium, $2 \%$ total phosphorus, $3 \% \mathrm{NaCl}$ and $2.7 \%$ lysine. The soft pellet feed with a diameter of $50 \mathrm{~mm}$ was made with a feed machine and stored at $-20{ }^{\circ} \mathrm{C}$ until use. Part of the water tank was replaced daily to remove waste and feces. When partially replacing the aquaculture water, an appropriate amount of L. plantarum, L. plantarum and C. butyricum was added to the PFDLP, PFDLR and PFDCB groups to maintain the concentration at $1 \times 10^{8} \mathrm{CFU} / \mathrm{mL}$. The water quality of each tank was kept within the best physical parameter range, temperature $\left(24.13 \pm 0.52{ }^{\circ} \mathrm{C}\right), \mathrm{pH}(7.41 \pm 0.15)$, ammonia-nitrogen $(0.27 \pm 0.05 \mathrm{mg} / \mathrm{L})$ and dissolved oxygen $(7.52 \pm 0.15 \mathrm{mg} / \mathrm{L})$, during the experiment.

\subsection{Proportion of Pellet Feed Recipients and Survival Analysis}

The number of pellet feed recipients in groups PFD, PFDLP, PFDLR and PFDCB were counted on days 7, 14 and 28 after pellet-feed feeding, and the proportion of pellet feed recipients (POPFR) was calculated according to the following formula: POPFR $(\%)=[\mathrm{Num}-$ ber of pellet feed recipients/Number of initial mandarin fish] $\times 100$. During the feeding trial, the number of deaths in each group was recorded every day, and Kaplan Meyer's (KM) survival analysis was used to evaluate the survival differences between groups.

\subsection{Sample Collection}

On days 7, 14 and 28 of pellet-feed feeding, twelve mandarin fish were randomly collected from each tank and then anesthetized with tricaine methanesulfonate (MS-222) for subsequent sampling. Blood samples collected from the tail vascular vein of each fish were placed in centrifuge tubes and centrifuged at $4{ }^{\circ} \mathrm{C}$ and $4000 \mathrm{rpm}$ for $15 \mathrm{~min}$ to separate the serum. The separated serum was stored at $-80^{\circ} \mathrm{C}$ for further determination of immune parameters. Brain and gut samples were collected and placed in RNA Later ${ }^{\circledR}$ (Qiagen, Hilden, Germany) at $4{ }^{\circ} \mathrm{C}$ overnight and then stored at $-80^{\circ} \mathrm{C}$ for gene expression analysis. A separate liver, intestine and gills were homogenized with cold phosphate buffer saline (PH 7.5). The homogenate was then centrifuged at $4{ }^{\circ} \mathrm{C}$ and $8000 \mathrm{rpm}$ for $10 \mathrm{~min}$, and the supernatant was taken and stored at $-20^{\circ} \mathrm{C}$ for analysis of antioxidants and oxidative stress parameters. Intestinal samples containing the inclusion were collected and placed in sterile Eppendorf tubes, immediately frozen in liquid nitrogen, and then stored at $-80{ }^{\circ} \mathrm{C}$ for microbiome analysis. Intestinal tissue was collected and fixed in Bouin's solution for $24 \mathrm{~h}$ before histological analysis was performed.

\subsection{Serum Parameter Analysis}

\subsubsection{Serum Lysozyme Content}

According to the instruction manual, lysozyme content in serum was strictly analyzed (Nanjing Jiancheng Bioengineering Institute, Nanjing, China).

\subsubsection{Measurement of IgM and CRP}

Reagent kits for immunoglobulin M (IgM) and C-reactive protein (CRP) were obtained from Shanghai Enzyme-linked Biotechnology Co., Ltd., Shanghai, China. Each parameter was strictly analyzed in accordance using a double-antibody sandwich ELISA with the manufacturer's instructions.

\subsection{Antioxidant and Oxidative Stress Parameters}

The superoxide dismutase (SOD) activity, CAT activity, glutathione (GSH) content and malondialdehyde (MDA) content were determined according to the instructions provided in the commercial kits (Nanjing Jiancheng Bioengineering Institute, Nanjing, China). SOD, GSH, CAT and MDA measurements were based on the WST-1 method [74], xanthine oxidase method [75], ammonium molybdate colorimetric method [76] and thiobarbituric acid method [77], respectively. 


\subsection{Gene Expression Analysis}

\subsubsection{Extraction of total RNA and Reverse Transcription}

According to the manufacturer's instructions, total RNAs were extracted from each tissue sample (50-100 mg) using RNAiso Plus reagent (Takara, Shiga, Japan). RNA concentrations and purity were determined using a Nanodrop 2000 c spectrophotometer (Thermo Fisher, Waltham, MA, USA). RNA was used as a templet for cDNA synthesis using PrimeScript ${ }^{\mathrm{TM}}$ reverse transcription (RT) reagent kit (TaKaRa, Shiga, Japan) following the manufacturer's guidelines and stored at $-80^{\circ} \mathrm{C}$ until analysis.

\subsubsection{Real-Time Quantitative PCR (RT-qPCR)}

Total RNA was isolated from different tissues by using RNAiso Plus reagent (Takara, Shiga, Japan) according to the manufacturer's instructions. First-strand complementary DNAs (cDNAs) were synthesized using PrimeScript ${ }^{\mathrm{TM}}$ RT reagent kit (Takara, Shiga, Japan) following the manufacturer's guidelines. The expression levels of ghrelin, leptin, npy, agrp and $\beta$-actin were detected using the corresponding forward and reverse primers, which were designed using Primer Express software (Applied Biosystems, Waltham, MA, USA) (Table 1). $\beta$-actin served as a housekeeping gene in order to normalize the expression levels. Quantitative PCR (qPCR) was performed on a total reaction volume of $10 \mu \mathrm{L}$, containing $0.2 \mu \mathrm{M}$ primers, $1 \mu \mathrm{L}$ of cDNA, $5 \mu \mathrm{L}$ of $2 \times$ SYBR premix ExTaq ${ }^{\mathrm{TM}}$ (Takara, Shiga, Japan) and $3.6 \mu \mathrm{L}$ of ultrapure water using the following setting: 40 cycles of amplification ( $5 \mathrm{~s}$ at $95^{\circ} \mathrm{C}, 40 \mathrm{~s}$ at $60^{\circ} \mathrm{C}$ and $1 \mathrm{~s}$ at $70^{\circ} \mathrm{C}$ ). All RT-qPCR reactions were performed in triplicate on a LightCycler 480 instrument (Roche Diagnostics, Rotkreuz, Switzerland). Data were analyzed using the $2^{-\Delta \Delta \mathrm{Ct}}$ method [78].

Table 1. Sequences of primer pairs used for real-time quantitative PCR in this study.

\begin{tabular}{|c|c|c|c|}
\hline Gene & Primer Name & Primer Sequence $\left(5^{\prime}-3^{\prime}\right)$ & Annealing Temp $\left({ }^{\circ} \mathrm{C}\right)$ \\
\hline \multirow[t]{2}{*}{ ghrelin } & Scghrelin-F & GCTTTCTCAGCССTTCAC & 60 \\
\hline & Scghrelin-R & GGTTGTCCTCAGTGGGTTG & \\
\hline \multirow[t]{2}{*}{ leptin } & scleptinB-F & CGAGAGTCACCTTTACCTG & 58 \\
\hline & scleptinB-R & GTGCAAATAAGCCTCTAAGTG & \\
\hline \multirow[t]{2}{*}{ npy } & scNPY-F & GCAAATCTCССТCTGACAATC & 60 \\
\hline & scNPY-R & GGTTTCACCGGGTATCCTT & \\
\hline \multirow[t]{2}{*}{ agrp } & scAgRP-F & GAGCCAAGCGAAGACCAGA & 58 \\
\hline & scAgRP-R & GCAGCACGGCAAATGAGAG & \\
\hline \multirow[t]{2}{*}{$\beta$-actin } & $\beta$-actin-F & СССТСТGAACСССАAAGCCA & 59 \\
\hline & $\beta$-actin-R & CAGCCTGGATGGCAACGTACA & \\
\hline
\end{tabular}

\subsection{Gut Microbiota Analysis}

Total bacterial DNA of the intestine samples with retained contents was extracted using an E.Z.N.A. ${ }^{\circledR}$ Stool DNA Kit (Omega, Norcross, GA, USA). After measurement of the concentration and quality of the extracted DNA using a Nanodrop 2000c spectrophotometer (Thermo Fisher, Waltham, MA, USA), the V4-V5 region of the bacterial 16S DNA gene was amplified via the PCR method using the primers of 515F (5'GTGCCAGCMGCCGCGGTAA-3') and 806R (5'-CCGTCAATTCCTTTG AGTTT- $3^{\prime}$ ). The high throughput sequencing for the qualified amplicon was performed on the Illumina NovaSeq6000 platform at Novogene Biotech Co., Ltd. (Beijing, China). Paired-end reads were assigned to samples based on a unique barcode and truncated by cutting off the barcode and primer sequence. The raw tags were then produced via FLASH (V1.2.7) [79]. Sequences were analyzed with the UCHIME algorithm [80] and QIIME [81]. The effective tags were filtered and clustered into operational taxonomic units (OTUs) under a $97 \%$ nucleotide similarity level. The taxonomic annotation of OTUs was performed using Uparse software [82]. The alpha diversity, including the observed species, Chao 1, abundancebased coverage estimator (ACE), Simpson, Shannon and PD whole tree, was calculated using QIIME (Version 1.9.1) to analyze the abundance and diversity. A Venn diagram was 
constructed to describe the core components of the genera. Beta diversity was evaluated using principal coordinates analysis (PCoA). Linear discriminant analysis effect size (LEfSe) was used to identify significant differences in the relative abundance of bacterial taxa [83]. Predicted functional pathways were annotated using the Kyoto encyclopedia of genes and genomes (KEGG) at level 1. Tax4Fun was used to predict the functional profile of the intestinal microbiota [84]. All figures were drawn using R software (Version 2.15.3).

\subsection{Intestinal Histological Assessment}

The foregut, midgut and hindgut tissues were fixed in Bouin's solution for $24 \mathrm{~h}$ and then dehydrated, embedded in paraffin and sectioned into 4- $\mu \mathrm{m}$ transverse cuts following the axis of the gut lumen. Hematoxylin and eosin (H.E.) were applied for the staining, and histological examination of the samples was carried out using an optic microscope (Nikon, Tokyo, Japan) with a digital camera (Nikon, Tokyo, Japan). The intestinal villi height and basement membrane thickness of each segment was measured with Image-Pro software.

\subsection{Statistical Analysis}

All the experimental data were tested for normality and homogeneity of variances using the Shapiro-Wilk's test and Levene's test, respectively, and presented as the mean \pm SEM. Significant differences were determined using the one-way analysis of variance (ANOVA) test, followed by Fisher's least significant difference post hoc test and Duncan's multiple range tests, after confirming data normality and homogeneity of variances. Statistical analysis was performed using SPSS software 19.0 (SPSS Inc., New York, NY, USA) and the Windows-based Graph pad prism statistical software (San Diego, CA, USA). A $p$ value less than 0.05 was accepted as statistically significant.

\section{Results}

\subsection{Proportion of Pellet Feed Recipients}

The POPFR of mandarin fish in different feeding groups (PFD, PFDCB, PFDLR and PFDLP) was tested on the 7 th, 14 th and 28 th day of feeding. As shown in Figure 1 , on the 28th day of feeding, the POPFR of mandarin fish in the PFDLP, PFDLR and PFDCB groups was higher than that in the PFD group, and the PFDLP and PFDCB groups reached a significant level of difference $(p<0.05)$. The highest POPFR of mandarin fish was recorded in PFDLP $(81 \%)$ compared to PFD $(68 \%)$ on the 28 th day of feeding.

\subsection{Survival Analysis}

Mandarin fish fed with pellet feed without probiotics supplemented had a lower survival rate than those fed with live bait at the end of the experiment (Figure 2). Application of L. plantarum, L. rhamnosus and C. butyricum significantly reduced the decrease of the survival rate of mandarin fish caused by the pellet feed diet at the end of the experiment (Figure 2).

\subsection{Serum Parameter Analysis}

\subsubsection{Serum Lysozyme Content}

Mandarin fish in the PFD group had lower serum lysozyme content than that in the LBFD group at days 7, 14 and 28 of feeding (Figure 3). The effects of L. plantarum, L. rhamnosus and C. butyricum on serum lysozyme content are shown in Figure 3. Application of L. plantarum, L. rhamnosus and C. butyricum reduced the decrease of the serum lysozyme content of mandarin fish caused by the pellet feed diet (Figure 3). Compared with the PFD group, the content of serum lysozyme increased significantly on the 7th and 28th day in the PFDLP group and on the 14 th day in the PFDLR group $(p<0.05)$ (Figure 3$)$. The highest serum lysozyme content of mandarin fish was noticed in PFDLP after being fed for 28 days (Figure 3 ). 


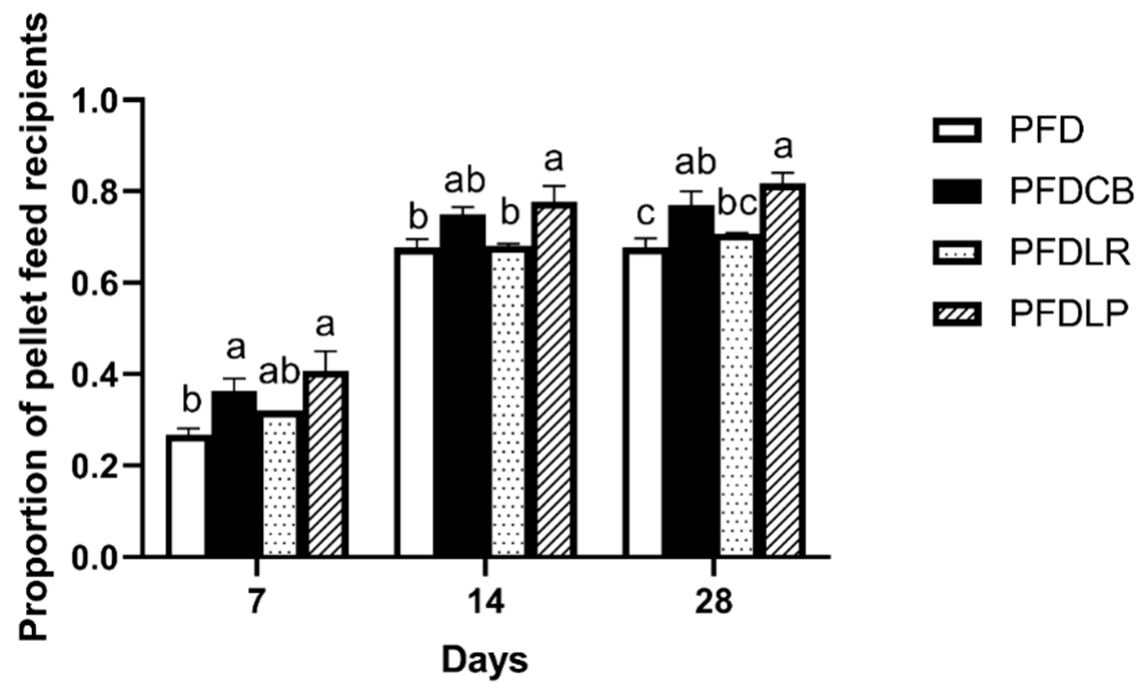

Figure 1. POPFR of mandarin fish in different feeding groups (PFD, PFDCB, PFDLR and PFDLP) at days 7, 14 and 28 of feeding. Data are presented as mean $\pm \operatorname{SEM}(n=3)$. Abbreviations: PFD, pellet-feed feeding group with probiotics free; PFDCB, pellet-feed feeding group with C. butyricum plus; PFDLR, pellet-feed feeding group with L. rhamnosus plus; PFDLP, pellet-feed feeding group with L. plantarum plus. A value followed by a lowercase superscript $(\mathrm{a}-\mathrm{c})$ differs significantly from all other values not followed by the same lowercase superscript at the same time point based on ANOVA followed by the post hoc test $(p<0.05)$.

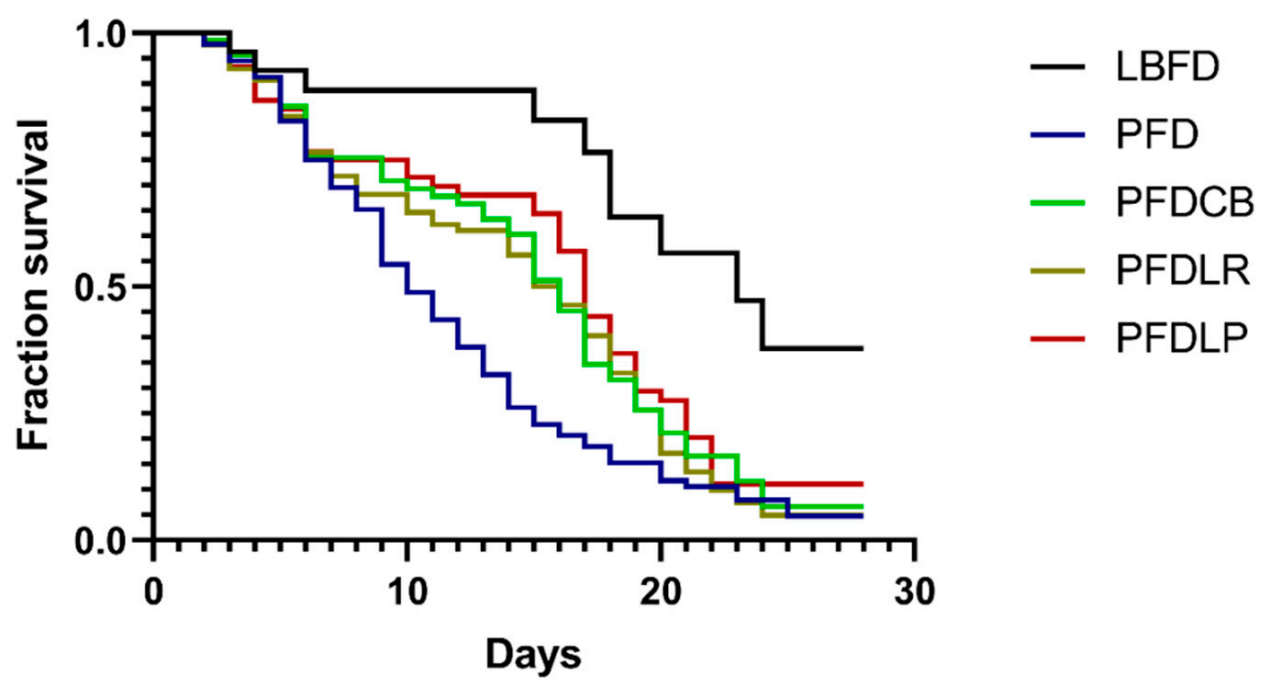

Figure 2. Kaplan Meyer's (KM) survival analysis of mandarin fish in different feeding groups (LBFD, PFD, PFDCB, PFDLR and PFDLP) during 28 days of feeding. Abbreviations: LBFD, live bait fish feeding group; PFD, pellet-feed feeding group with probiotics free; PFDCB, pellet-feed feeding group with C. butyricum plus; PFDLR, pellet-feed feeding group with L. rhamnosus plus; PFDLP, pellet-feed feeding group with L. plantarum plus. 


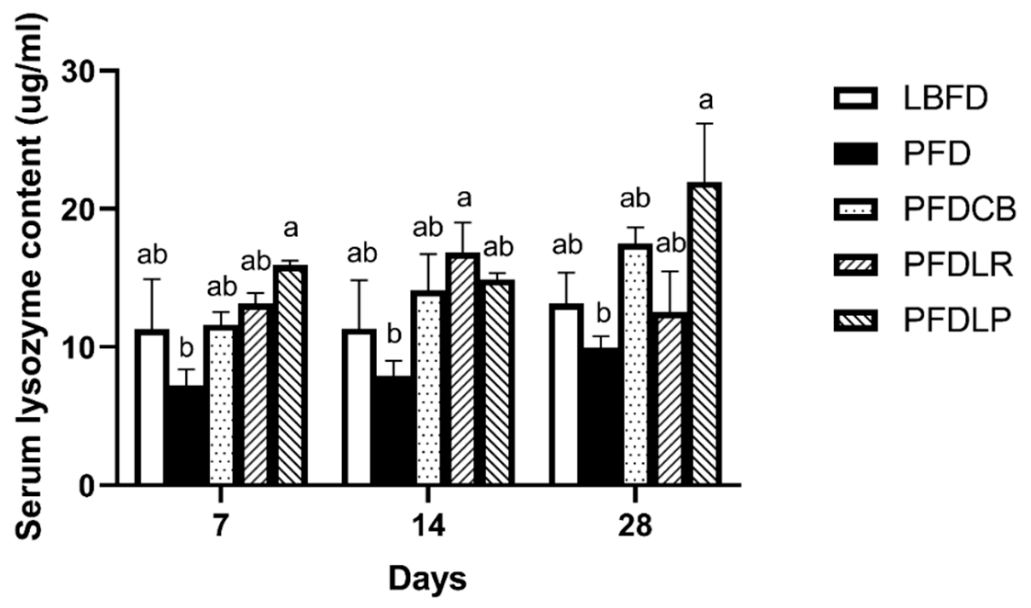

Figure 3. Serum lysozyme content of mandarin fish in different feeding groups (LBFD, PFD, PFDCB, PFDLR and PFDLP) at day 7, 14 and 28 of feeding. Data are presented as mean \pm SEM $(n=9)$. Abbreviations: LBFD, live bait fish feeding group; PFD, pellet-feed feeding group with probiotics free; PFDCB, pellet-feed feeding group with C. butyricum plus; PFDLR, pellet-feed feeding group with L. rhamnosus plus; PFDLP, pellet-feed feeding group with L. plantarum plus. A value followed by a lowercase superscript $(a-b)$ differs significantly from all other values not followed by the same lowercase superscript at the same time point based on ANOVA followed by the post hoc test $(p<0.05)$.

\subsubsection{Measurement of IgM and CRP}

The effects of L. plantarum, L. rhamnosus and C. butyricum on serum IgM and CRP content are shown in Figure 4. Although the application of L. plantarum, L. rhamnosus and C. butyricum reduced the decrease of the serum IgM level of mandarin fish at days 14 and 28 of feeding (Figure 4A), serum CRP content was not significantly affected by pellet feed and probiotics application (Figure 4B). Compared with the PFD group, the serum IgM content of the PFDLP group supplemented with L. plantarum was significantly increased at days 14 and 28 of feeding $(p<0.05)$ (Figure $4 \mathrm{~A})$.

A

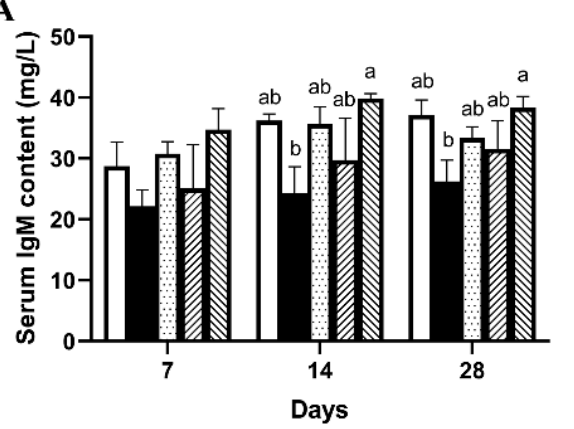

B

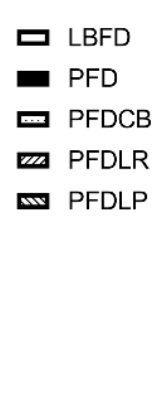

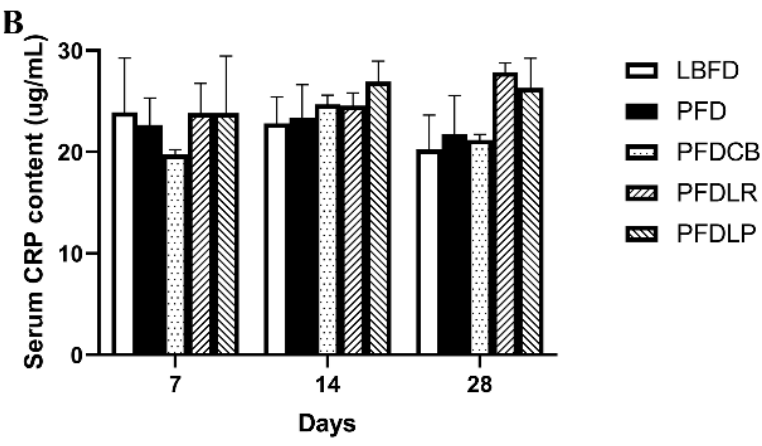

Figure 4. Serum content of $\operatorname{IgM}(\mathbf{A})$ and CRP (B) of mandarin fish in different feeding groups (LBFD, PFD, PFDCB, PFDLR and PFDLP) at day 7, 14 and 28 of feeding. Data are presented as mean $\pm \operatorname{SEM}(n=9)$. Abbreviations: IgM, immunoglobulin M; CRP, C-reactive protein; LBFD, live bait fish feeding group; PFD, pellet-feed feeding group with probiotics free; PFDCB, pellet-feed feeding group with C. butyricum plus; PFDLR, pellet-feed feeding group with L. rhamnosus plus; PFDLP, pelletfeed feeding group with L. plantarum plus. A value followed by a lowercase superscript $(\mathrm{a}-\mathrm{b})$ differs significantly from all other values not followed by the same lowercase superscript at the same time point based on ANOVA followed by the post hoc test $(p<0.05)$.

\subsection{Antioxidant and Oxidative Stress Parameters}

GSH content and CAT activity in liver, gut and gill of mandarin fish in the PFD group were decreased compared with that in the LBFD group (Figure 5B,C), while the MDA level in liver, gut and gill was increased (Figure 5D). Compared with the LBFD group, 
the decrease of GSH content in gut, the decrease of CAT activity in gill and the increase of MDA content in gill in the PFD group reached significant difference levels $(p<0.05)$ (Figure 5B-D). The application of L. plantarum, L. rhamnosus and C. butyricum motivated an elevation of GSH content and CAT activity (Figure 5B,C) and a reduced MDA content in the liver, gut and gill of mandarin fish in the PFDLP, PFDLR and PFDCB groups when compared to the PFD group (Figure 5D). The content of GSH in liver and gill of mandarin fish in the PFDLP group treated with L. plantarum was significantly higher than that in the PFD group $(p<0.05)$ (Figure 5B). Compared with the mandarin fish in the PFD group, application of L. plantarum, L. rhamnosus and C. butyricum significantly increased CAT activity in liver and MDA content in gill $(p<0.05)$ (Figure 5C,D).
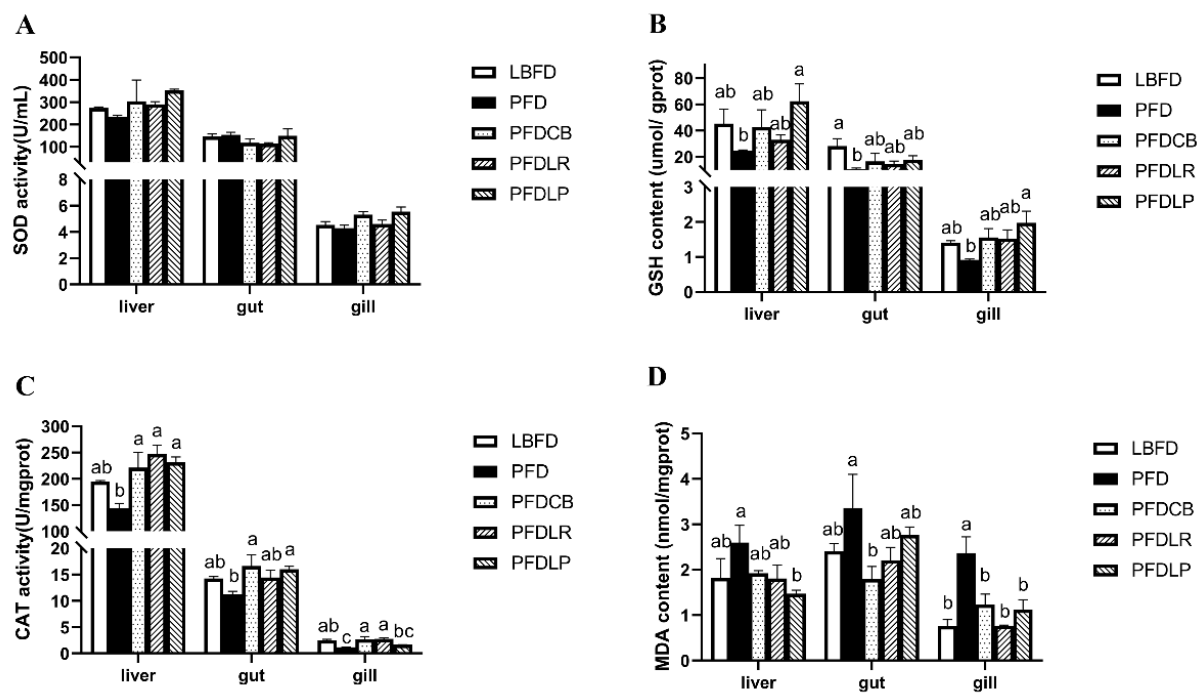

Figure 5. Activities of SOD (A), GSH (B) and CAT (C) and content of MDA (D) in the gut, liver and gills of mandarin fish in different feeding groups (LBFD, PFD, PFDCB, PFDLR and PFDLP) after being fed for 28 days. Data are presented as mean \pm SEM $(n=9)$. Abbreviations: SOD, superoxide dismutase; GSH, glutathione; CAT, Catalase; MDA, malondialdehyde; LBFD, live bait fish feeding group; PFD, pellet-feed feeding group with probiotics free; PFDCB, pellet-feed feeding group with C. butyricum plus; PFDLR, pellet-feed feeding group with L. rhamnosus plus; PFDLP, pellet-feed feeding group with $L$. plantarum plus. A value followed by a lowercase superscript $(\mathrm{a}-\mathrm{c})$ differs significantly from all other values not followed by the same lowercase superscript at the same time point based on ANOVA followed by the post hoc test $(p<0.05)$.

\subsection{Expression of Appetite-Related Genes}

For appetite control genes expression in the brain and gut of mandarin fish in different feeding groups (LBFD, PFD, PFDCB, PFDLR and PFDLP) after being fed for 28 days, we found a significantly increased mRNA level of leptin in the gut of mandarin fish and a significantly decreased mRNA level of npy and agrp in the brain of mandarin fish in the PFD group compared to the LBFD group $(p<0.05)$ (Figure 6A,B). After applying L. plantarum, L. rhamnosus and C. butyricum, the leptin expression levels in the mandarin fish gut were significantly down-regulated in the PFDLP and PFDCB groups compared with that in the PFD group $(p<0.05)$ (Figure 6A,B). The agrp expression levels in the mandarin fish brain were significantly up-regulated in the PFDLP, PFDLR and PFDCB groups compared with that in the PFD group $(p<0.05)$ (Figure $6 \mathrm{~A}, \mathrm{~B})$. 
A

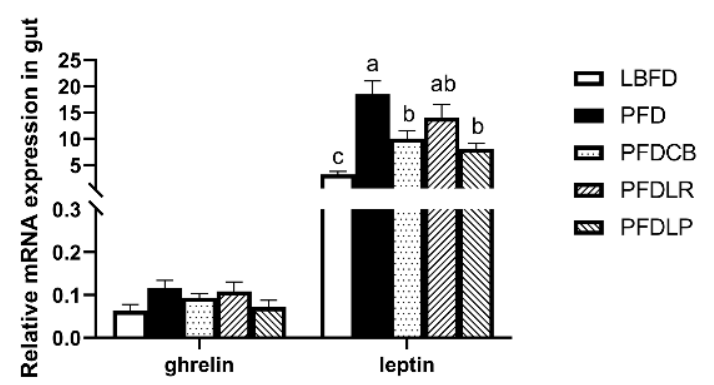

B

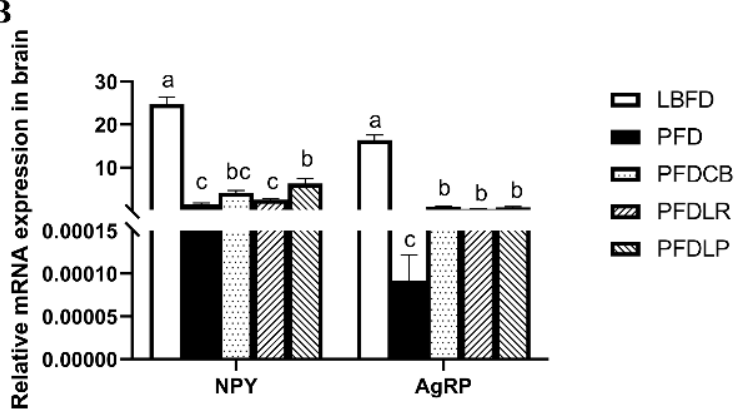

Figure 6. Relative mRNA expressions of appetite control genes in the gut (A) and brain (B) of mandarin fish in different feeding groups (LBFD, PFD, PFDCB, PFDLR and PFDLP) after being fed for 28 days. Data are presented as mean \pm SEM $(n=9)$. Abbreviations: NPY, nerve peptide y; AgRP, agouti gene-related protein; LBFD, live bait fish feeding group; PFD, pellet-feed feeding group with probiotics free; PFDCB, pellet-feed feeding group with C. butyricum plus; PFDLR, pellet-feed feeding group with L. rhamnosus plus; PFDLP, pellet-feed feeding group with L. plantarum plus. Data are presented as mean \pm SEM $(n=9)$. A value followed by a lowercase superscript $(a-c)$ differs significantly from all other values not followed by the same lowercase superscript at the same time point based on ANOVA followed by the post hoc test $(p<0.05)$.

\subsection{Gut Microbiota Analysis \\ 3.6.1. Richness and Diversity}

The alpha diversity index, including observed species, Shannon, Simpson, Chao 1, $\mathrm{ACE}$ and PD whole tree, was calculated to assess the diversity and richness of intestinal microbiota of mandarin fish in different groups. No significant difference was observed in the Shannon and Simpson indices between groups $(p<0.05)$ (Table 2). The observed species, Chao1, ACE and PD whole tree indices of the PFDLP group were higher than that of other groups, and there was significant difference compared with the LBFD and PFDCB groups $(p<0.05)$ (Table 2). A Venn diagram was constructed to identify the core and different OTUs existing in mandarin fish under different feeding strategies. In this regard, 168 OTUs were shared among all mandarin fish gut samples. In contrast, 430 OTUs, 534 OTUs, 661 OTUs, 269 OTUs and 176 OTUs were unique to LBFD, PFD, PFDLP, PFDLR and PFDCB groups, respectively (Figure 7). Simultaneously, the intestinal microbiota community structure was further investigated using PCoA based on the binary jaccard distance (Figure 8). PCoA analysis showed $16.8 \%$ and $12.16 \%$ explained variance of principal component analysis PCoA1 and PCoA2, respectively. PCoA cluster analysis indicated that three clusters were formed and separated between the bait fish diet group (LBFD), pellet feed group (PFD) and probiotic-treated pellet feed group (PFDLP, PFDLR and PFDCB) after being fed for 28 days (Figure 8 ). This suggested that different feeding strategies of mandarin fish led to different intestinal community structures (Figure 8).

Table 2. Richness and diversity indices of mandarin fish intestinal microbial populations in different feeding groups (LBFD, PFD, PFDCB, PFDLR and PFDLP) after being fed for 28 days.

\begin{tabular}{cccccc}
\hline Index & LBFD & PFD & PFDCB & PFDLR & PFDLP \\
\hline Observed species & $418.33 \pm 107.84^{\mathrm{c}}$ & $721.00 \pm 66.55^{\mathrm{a}, \mathrm{b}}$ & $435.75 \pm 18.91^{\mathrm{c}}$ & $493.75 \pm 85.17^{\mathrm{b}, \mathrm{c}}$ & $777.25 \pm 35.03^{\mathrm{a}}$ \\
Shannon & $2.61 \pm 125.16^{\mathrm{a}}$ & $2.85 \pm 39.55^{\mathrm{a}}$ & $1.88 \pm 22.37^{\mathrm{a}}$ & $1.62 \pm 126.45^{\mathrm{a}}$ & $2.85 \pm 12.40^{\mathrm{a}}$ \\
Simpson & $0.71 \pm 151.35^{\mathrm{a}}$ & $0.59 \pm 47.19^{\mathrm{a}}$ & $0.49 \pm 16.06^{\mathrm{a}}$ & $0.41 \pm 131.67^{\mathrm{a}}$ & $0.55 \pm 29.14^{\mathrm{a}}$ \\
Chao 1 & $579.12 \pm 0.51^{\mathrm{b}, \mathrm{c}}$ & $859.22 \pm 0.10^{\mathrm{a}, \mathrm{b}}$ & $556.92 \pm 0.34^{\mathrm{c}}$ & $692.79 \pm 0.35^{\mathrm{a}, \mathrm{b}, \mathrm{c}}$ & $918.94 \pm 0.33^{\mathrm{a}}$ \\
ACE & $612.28 \pm 0.07^{\mathrm{b}}$ & $902.63 \pm 0.07^{\mathrm{a}, \mathrm{b}}$ & $588.27 \pm 0.12^{\mathrm{b}}$ & $722.63 \pm 0.12^{\mathrm{a}, \mathrm{b}}$ & $993.75 \pm 0.05^{\mathrm{a}}$ \\
PD whole tree & $68.41 \pm 15.70^{\mathrm{b}}$ & $85.20 \pm 5.46^{\mathrm{b}}$ & $80.21 \pm 16.99^{\mathrm{b}}$ & $169.72 \pm 44.11^{\mathrm{a}, \mathrm{b}}$ & $199.00 \pm 36.99^{\mathrm{a}}$ \\
\hline
\end{tabular}

ACE: abundance-based coverage estimator; LBFD, live bait fish feeding group; PFD, pellet-feed feeding group with probiotics free; PFDCB, pellet-feed feeding group with C. butyricum plus; PFDLR, pellet-feed feeding group with L. rhamnosus plus; PFDLP, pellet-feed feeding group with $L$. plantarum plus. The numbers represent the mean $\pm \operatorname{SEM}(n=3)$. A value followed by a lowercase superscript $(a-c)$ differs significantly from all other values not followed by the same lowercase superscript at the same time point based on ANOVA followed by the post hoc test $(p<0.05)$. 


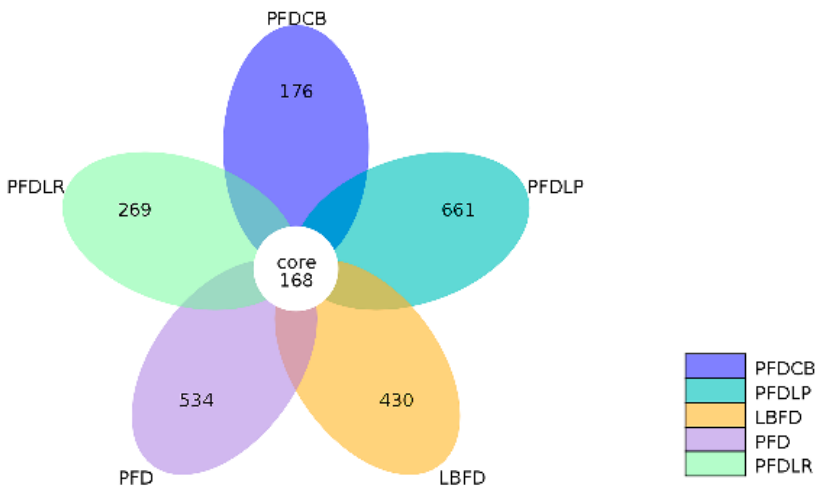

Figure 7. Venn diagram analysis depicting the numbers of shared and unique OTUs of mandarin fish intestinal microbial populations in different feeding groups (LBFD, PFD, PFDCB, PFDLR and PFDLP) after being fed for 28 days. Abbreviations: LBFD, live bait fish feeding group; PFD, pelletfeed feeding group with probiotics free; PFDCB, pellet-feed feeding group with C. butyricum plus; PFDLR, pellet-feed feeding group with L. rhamnosus plus; PFDLP, pellet-feed feeding group with L. plantarum plus.

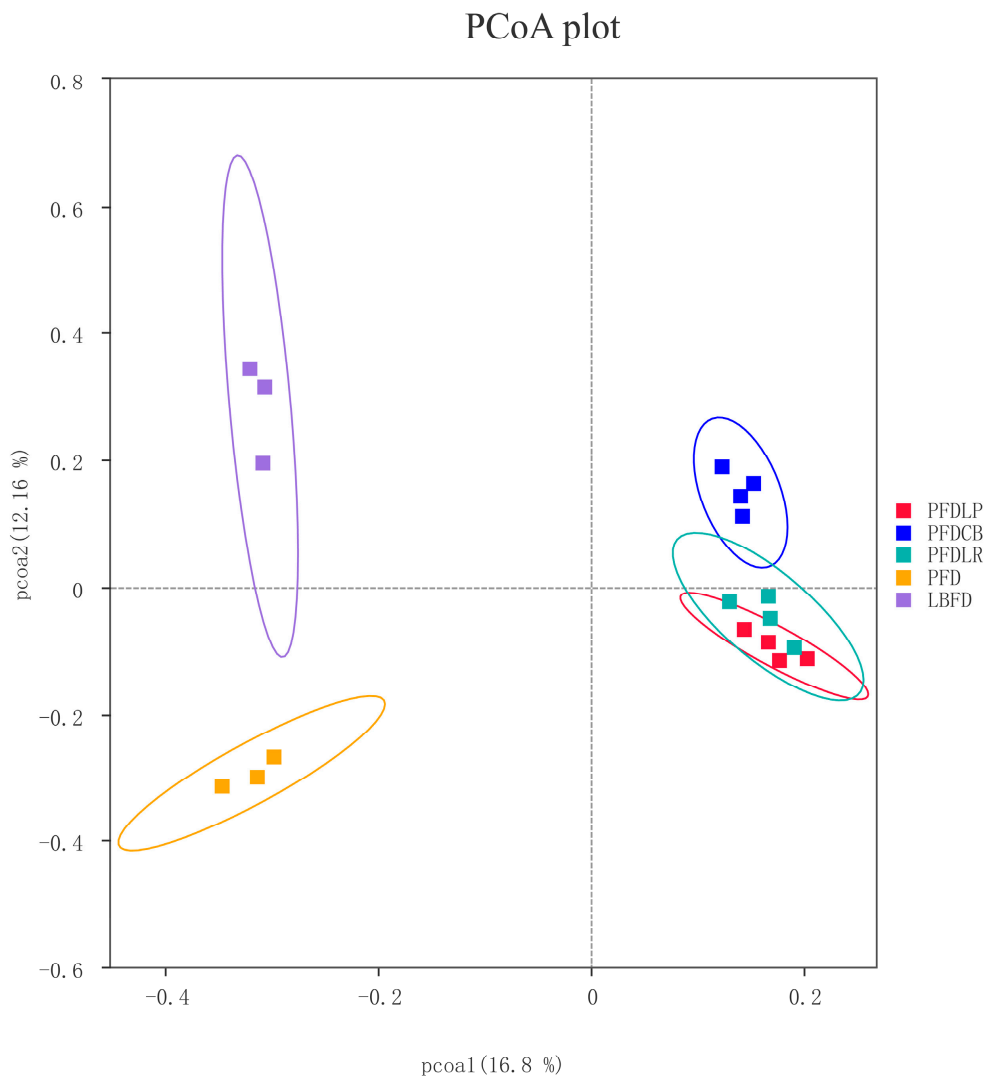

Figure 8. PCoA based on the binary jaccard distance of the intestinal bacterial communities of mandarin fish in different feeding groups (LBFD, PFD, PFDCB, PFDLR and PFDLP) after being fed for 28 days. Abbreviations: LBFD, live bait fish feeding group; PFD, pellet-feed feeding group with probiotics free; PFDCB, pellet-feed feeding group with C. butyricum plus; PFDLR, pellet-feed feeding group with L. rhamnosus plus; PFDLP, pellet-feed feeding group with L. plantarum plus.

\subsubsection{Community Composition and Biomarker Analysis}

The gut microbiota of mandarin fish in different feeding groups (LBFD, PFD, PFDCB, PFDLR and PFDLP) showed their unique microbial population structure. At the phylum and genus level, the top 10 abundant microbiota composition in the intestine of mandarin 
fish in different feeding groups (LBFD, PFD, PFDCB, PFDLR and PFDLP) after being fed for 28 days is represented in Figure 9. The gut microbiota of mandarin fish in the LBFD group was dominated by Fusobacteriota and Proteobacteria at the phylum level, and Proteobacteria was the dominant phylum in the gut microbiota of the PFD, PFDLP, PFDLR and PFDCB groups (Figure 9A). The abundance of Aeromonas in the PFDLP, PFDLR and PFDCB groups was significantly lower than in the PFD group (Figure 9B). LEfSe analysis revealed 19, 24, 17,7 and 1 biomarkers with significantly higher relative abundance in the LBFD, PFD, PFDLP, PFDLR and PFDCB groups, respectively (Figure 10A). Aeromonas was a biomarker for PFD compared with other groups (Figure 10B).

A

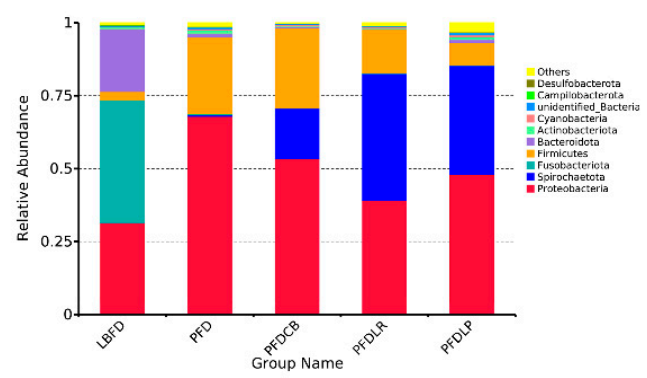

B

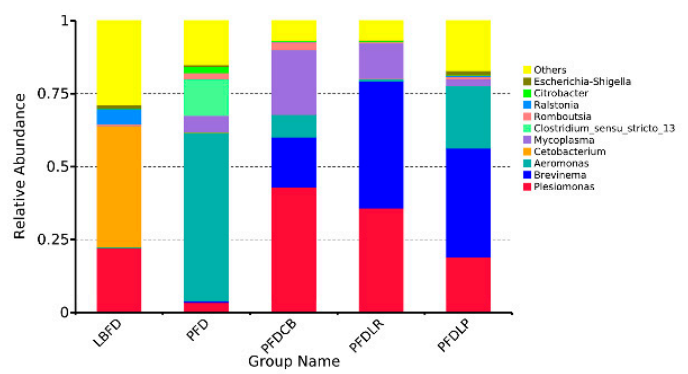

Figure 9. The abundance of composition at phylum (A) and genus (B) level in mandarin fish intestinal microbial populations in different feeding groups (LBFD, PFD, PFDCB, PFDLR and PFDLP) after being fed for 28 days. Abbreviations: LBFD, live bait fish feeding group; PFD, pellet-feed feeding group with probiotics free; PFDCB, pellet-feed feeding group with C. butyricum plus; PFDLR, pellet-feed feeding group with L. rhamnosus plus; PFDLP, pellet-feed feeding group with L. plantarum plus.

A

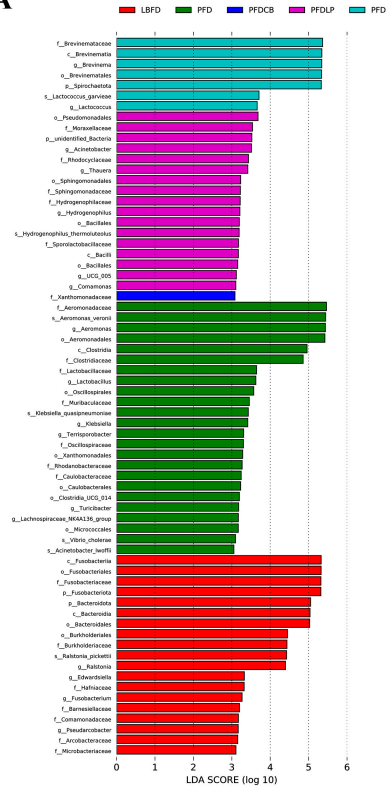

B

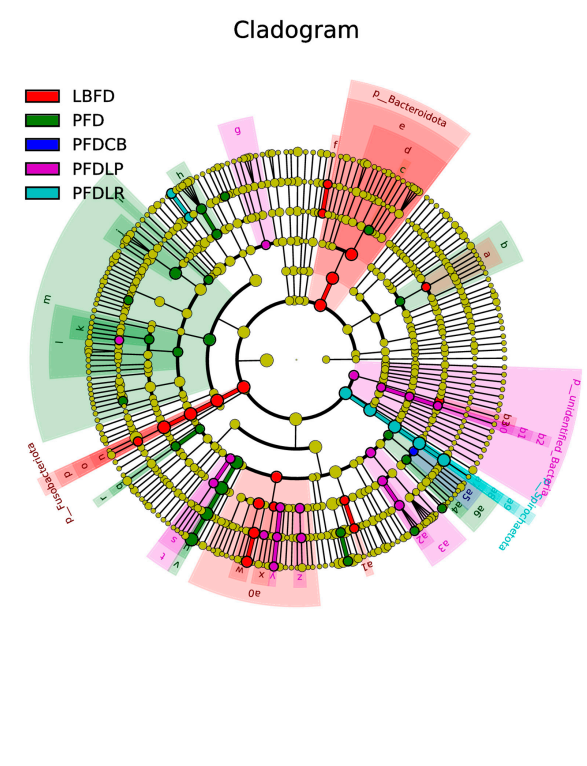

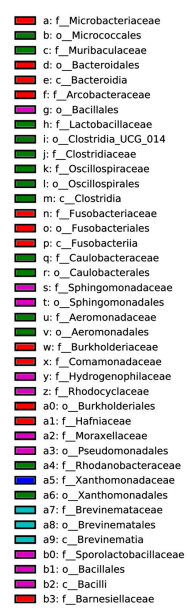

Figure 10. Intergroup variation in the relative abundance of the intestinal microbial communities. (A) Cladogram of LEfSe. (B) Bacterial taxa differentially displayed in the mandarin fish intestinal microbial populations in different feeding groups (LBFD, PFD, PFDCB, PFDLR and PFDLP) after being fed for 28 days were identified via LEfSe using an LDA score threshold of $>3$. Abbreviations: LBFD, live bait fish feeding group; PFD, pellet-feed feeding group with probiotics free; PFDCB, pellet-feed feeding group with C. butyricum plus; PFDLR, pellet-feed feeding group with L. rhamnosus plus; PFDLP, pellet-feed feeding group with L. plantarum plus. 


\subsubsection{Functional Prediction}

Functional prediction on the KEGG database was annotated based on $16 \mathrm{~S}$ sequencing data. As shown in Figure 11, the abundance of functional categories based on KEGG (level 1) between different feeding groups (LBFD, PFD, PFDCB, PFDLR and PFDLP) after being fed for 28 days were analyzed. The abundance of human pathogens pneumonia and human pathogens nosocomial significantly increased in the PFD group compared with other groups $(p<0.05)$ (Figure 11).

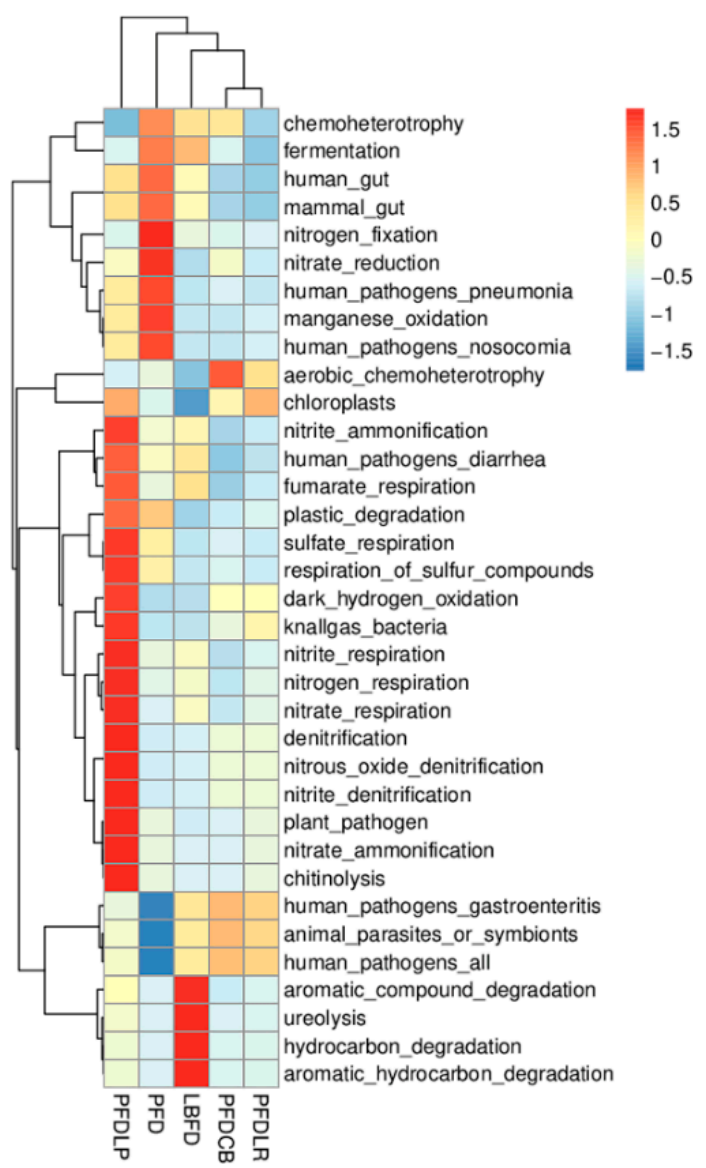

Figure 11. Heatmap showing the relative abundances of KEGG ortholog groups of mandarin fish intestinal microbial populations in different feeding groups (LBFD, PFD, PFDCB, PFDLR and PFDLP) after being fed for 28 days. The heatmap was made based on Tax4Fun functional annotations, and the color intensity indicates the abundance information. Abbreviations: LBFD, live bait fish feeding group; PFD, pellet-feed feeding group with probiotics free; PFDCB, pellet-feed feeding group with C. butyricum plus; PFDLR, pellet-feed feeding group with L. rhamnosus plus; PFDLP, pellet-feed feeding group with L. plantarum plus.

\subsection{Intestinal Histological Assessment}

Histological changes of the intestinal tract were observed in different feeding groups (LBFD, PFD, PFDCB, PFDLR and PFDLP) after being fed for 28 days (Figure 12). By comparing LBFD, PFD, PFDCB, PFDLR and PFDLP, the result showed that C. butyricum, L. rhamnosus and L. plantarum could significantly increase the villi height of the foregut, midgut and hindgut of mandarin fish fed with pellet feed $(p<0.05$; Figure 13A) and significantly reverse the decrease in the thickness of foregut basement membrane caused by pellet-feed feeding ( $p<0.05$; Figure 13B). 


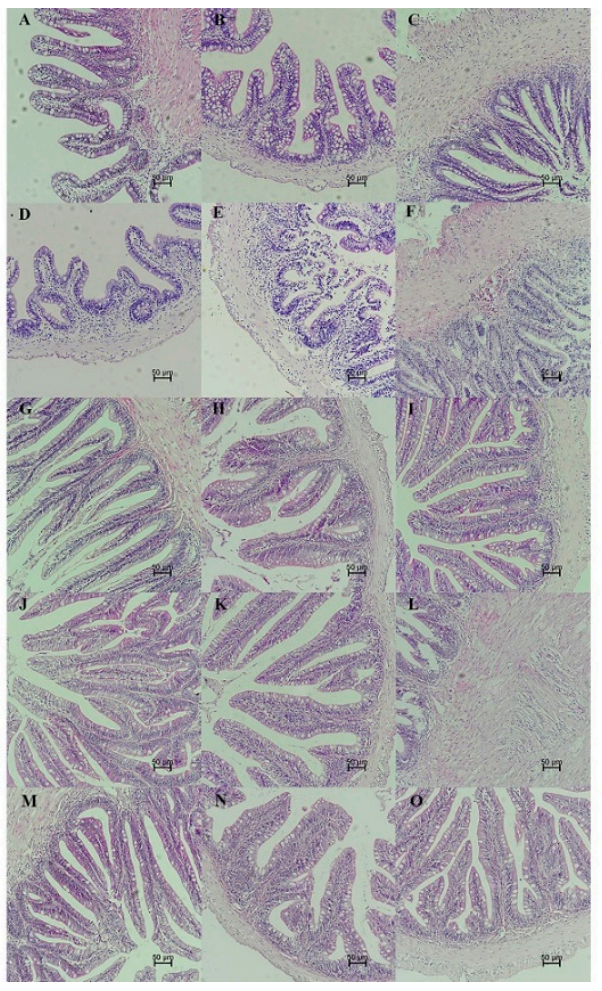

Figure 12. Photomicrographs showing histological sections of the intestinal tract of mandarin fish in different feeding groups (LBFD, PFD, PFDCB, PFDLR and PFDLP) after being fed for 28 days. (H.E. staining; scale bar: $50 \mu \mathrm{m}$; magnification $\times 200$ ). (A-C) Foregut, midgut and hindgut of mandarin fish in LBFD group. (D-F) Foregut, midgut and hindgut of mandarin fish in PFD group. (G-I) Foregut, midgut and hindgut of mandarin fish in PFDCB group. (J-L) Foregut, midgut and hindgut of mandarin fish in PFDLR group. (M-O) Foregut, midgut and hindgut of mandarin fish in PFDLP group. Abbreviations: H.E., hematoxylin and eosin staining; LBFD, live bait fish feeding group; PFD, pellet-feed feeding group with probiotics free; PFDCB, pellet-feed feeding group with C. butyricum plus; PFDLR, pellet-feed feeding group with L. rhamnosus plus; PFDLP, pellet-feed feeding group with L. plantarum plus.

A

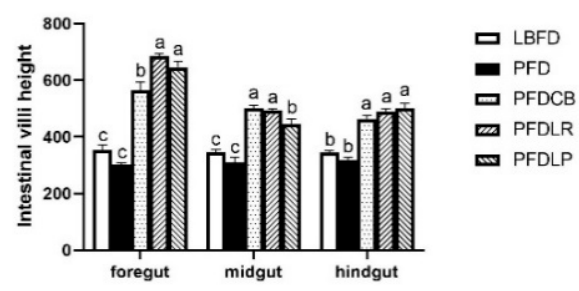

B

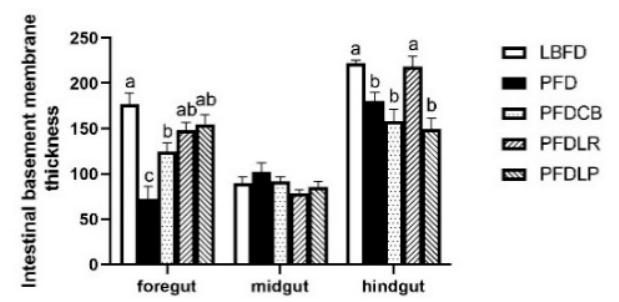

Figure 13. Intestinal villi height (A) and basement membrane thickness (B) of mandarin fish in different feeding groups (LBFD, PFD, PFDCB, PFDLR and PFDLP) after being fed for 28 days. Data are presented as mean \pm SEM $(n=3)$. Abbreviations: LBFD, live bait fish feeding group; PFD, pellet-feed feeding group with probiotics free; PFDCB, pellet-feed feeding group with $C$. butyricum plus; PFDLR, pellet-feed feeding group with L. rhamnosus plus; PFDLP, pellet-feed feeding group with L. plantarum plus. A value followed by a lowercase superscript $(\mathrm{a}-\mathrm{c})$ differs significantly from all other values not followed by the same lowercase superscript at the same time point based on ANOVA followed by the post hoc test $(p<0.05)$. 


\section{Discussion}

Mandarin fish have a food preference for live bait and show certain eating disorders with dead bait fish or pellet feed. The increased mortality rate of mandarin fish under pellet feeding conditions seriously affects its economic benefits $[10,66]$. The eating disorder is characterized by abnormal feeding behaviors associated with the establishment of food preference $[1-3,6]$. Gut microbiota can regulate host food preferences through interactions with nutritional, immune, antioxidant stress and appetite levels [26,85]. Previous studies have shown that probiotics can influence the feeding behavior of the host by regulating the microbiota $[26,27,86]$. However, few studies have been done on the regulatory effect of probiotics on eating disorders, especially on the pellet feed intake of mandarin fish [87]. Therefore, the present study was conducted to assess the effects of L. plantarum, L. rhamnosus and C. butyricum on the POPFR, survival, appetite, gut microbiota, innate immunity, antioxidant capacity and intestinal histology in mandarin fish and to explore the role of probiotics in regulating feeding behavior in vivo.

Acceptance of pelleted feed and survival rate are direct indicators of the improvement of eating disorders during the feeding process of mandarin fish with pellet feed. In this study, we observed that supplementation with either of the three probiotics effectively increased the POPFR in mandarin fish compared to those fed the same diet but without probiotics supplementation. Moreover, pellet feed diet can lead to the reduction of survival rate of mandarin fish, which is consistent with the previous report that the dietary conversion of Sparus aurata larvae and Solea senegalensis larvae from live bait to alginate microdiets resulted in a significant decrease in survival rate, which may be related to the changes of physiological stress and nutritional status of the larvae fish [88-90]. Results showed that L. plantarum, L. rhamnosus and C. butyricum can significantly reverse the increase in mortality of mandarin fish caused by feeding pellets at the end of the 28-day experiment. This finding is consistent with a previous study in which the administration of L. plantarum to the rainbow trout at a dose of $10^{6} \mathrm{CFU} / \mathrm{g}$ for 36 consecutive days significantly improved the survival rate of rainbow trout when attacked by Lactococcus garvieae [91]. Similarly, Hooshyar reported that $L$. rhamnosus ATCC 7469 significantly increased the survival rate of rainbow trout (Oncorhynchus mykiss) when attacked by Yersinia ruckeri [36]. Duan reported that supplementation of C. butyricum $\left(1 \times 10^{9} \mathrm{CFU} / \mathrm{g}\right)$ for 56 days improved the survival of black tiger shrimp (Penaeus monodon) after exposure to nitrite stress for 24 and $48 \mathrm{~h}$ [92]. Proper nutrition can affect intestinal health through several pathways, including intestinal morphology, microbial diversity, intestinal barriers and oxidative status [93]. The improvement of survival of cultured animals after applying L. rhamnosus, L. plantarum and C. butyricum may result from their positive regulation of nutritional status, intestinal morphology, gut microbiota, oxidative status and immune system [38,94,95]. Therefore, the administration of probiotics may be a potential method to improve the eating disorders of mandarin fish caused by pellet feed and increase the POPFR of mandarin fish without side effects because probiotics such as L. plantarum, L. rhamnosus and C. butyricum are generally regarded as safe for aquatic animals.

Appetite is one reason influencing the eating preference of mandarin fish [96]. Feeding behavior is ultimately regulated by central feeding centers of the brain, which receive and process information from endocrine signals from both the brain and periphery. These signals, such as hormones that inhibit (e.g., leptin) or increase (e.g., Agrp) ingestion, provide information about nutritional status and ingestion [97-99]. Npy is considered the most potent orexigenic molecule in fish, mediated by gut microbiota changes [100,101]. Agrp is one of the most potent appetite stimulants within the hypothalamus and mediates the peripheral body weight regulators such as ghrelin and leptin $[100,102]$. In the present study, we observed that L. rhamnosus, L. plantarum and C. butyricum could reverse the decrease of agrp expression in the brain tissue of mandarin fish caused by pellet-feed feeding. At the peripheral level, ghrelin is a potent appetite stimulant and is highly expressed in the fish gut $[103,104]$. Furthermore, the gastrointestinal hormone ghrelin is a vital molecule that regulates intestinal motility and secretion $[105,106]$. Leptin plays an anorexic role 
by down-regulating orexigenic signals such as Npy [107]. This study showed that the treatment of L. rhamnosus, L. plantarum and C. butyricum can reverse the high expression of the peripheral hormone leptin in the intestinal tissue of mandarin fish caused by feed-pellet feeding. These results agree with the previous findings on the regulation of appetite of L. rhamnosus on larval Nile tilapia [38]. All this indicates that probiotics treatment can promote the appetite of pellet feeding mandarin fish through reducing the expression of the peripheral appetite-suppressing hormone leptin and increasing the expression of the central appetite-promoting factor Npy / Agrp. Previous studies have shown that the gut microbiota can affect host appetite and eating behavior by directly affecting nutrient sensing and the satiety regulation system [26]. In this study, the appetite-promoting effect of L. rhamnosus, L. plantarum and C. butyricum may be mediated by their regulation on the gut microbiota of mandarin fish.

The immune system can influence eating behavior through interactions with gut bacteria and appetite $[108,109]$. As lower vertebrates, fish mainly rely on the innate immune system to resist pathogens [110]. Lysozyme is responsible for bacterial lysis and activation of phagocytes and complement systems [111]. IgM mainly exists in the serum, which is the most essential component of teleost humoral immunity, and it can recognize, bind and precipitate antigens and activate the complement system [112]. To assess if L. rhamnosus, L. plantarum, C. butyricum affects the immune system of feed-fed mandarin fish, we measured the levels of lysozyme and IgM in the serum. We found that at the end of 28 days of cultivation, the three probiotics can increase the reduction of mandarin fish serum lysozyme and IgM content caused by pellet feed domestication, and L. plantarum is the most significant. All this is similar to the finding in a previous publication suggesting that the feed supplement of L. plantarum CCFM8661 restored the decrease in serum lysozyme of Nile tilapia caused by waterborne Pb exposure [113]. In Wang's study, administration of C. butyricum significantly increased the serum IgM levels in piglets on day 28 [114]. Liao et al. have confirmed that a diet supplemented with C. butyricum increased the IgM concentration compared with that of chicks in the control group at 21 and 42 days old [115]. This study proved that the addition of L. plantarum, L. rhamnosus and C. butyricum reversed the decrease in serum lysozyme and IgM content caused by pellet-feed feeding, which may further ameliorate eating disorders by regulating the appetite and gut microbiota of mandarin fish.

Anti-oxidative enzymes are the major components of anti-oxidative defense systems in living organisms [116]. The host gut microbiota directly or indirectly influences the central nervous system by affecting local OS levels and the permeability of the gut and then influences the behavioral characteristics of the host. SOD, CAT and GSH are considered the three main antioxidant enzymes in the primary antioxidant defense system, eliminating ROS in the body during oxidative damage [117]. MDA is an essential product of membrane lipid peroxidation and a well-known aging indicator reflecting the degree of oxidative stress in cells [118]. In this study, compared with the LBFD group, the decrease of GSH content in gut, the decrease of CAT activity in gill and the increase of MDA content in gill in the PFD group reached significant difference levels $(p<0.05)$, indicating that the pellet diet induced oxidative stress in mandarin fish, which is in accord with the results found in Solea senegalensis larvae and hybrid mandarin fish $[88,119]$. The low nutritional status and stress caused by the pellet diet may decrease antioxidant capacity in mandarin fish [88,120-124]. Furthermore, compared with the mandarin fish in the PFD group, application of L. plantarum, L. rhamnosus and C. butyricum significantly increased CAT activity in liver and MDA content in gill $(p<0.05)$. Increased CAT activity and GSH content accompanied by decreased MDA levels was observed after the application of three probiotics compared with the PFD group, which indicates that L. rhamnosus, L. plantarum and C. butyricum could enhance the antioxidant capacity of the host, which is consistent with the findings in rainbow trout, the black tiger shrimp (Penaeus monodon) and Nile tilapia $[36,92,113,125]$. The three kinds of probiotics showed an excellent free radical scavenging ability in the 
oxidative damage of the liver, intestine, and gill tissues, which may be attributed to its ability in gut microbiota and immune system regulation.

It has been reported that gut microbiota plays a causal role in regulating the feeding behavior of the host and can directly or indirectly affect the appetite and food intake of the host $[26,126]$. The composition of the intestinal microbiome is influenced by both host genotype and environment. Previous studies have shown that the gut microbiota of aquatic species is influenced by several abiotic factors $[127,128]$. Diet is considered one way to change the gut microbiota and the exogenous factors affecting the gut microbiota [129-138]. In this study, compared with the live bait fish diet, the pellet feed diet changed the intestinal colony structure of mandarin fish, which may be mainly caused by changes in the dietary structure and also be affected by environmental stress (including dietary stress) [139]. Disturbance of gut microbiota balance could lead to the establishment of harmful bacteria, causing disease problems [140-143]. In addition to diet, probiotic treatments can also affect the gut microbiome [144,145]. Probiotics play an essential role in the welfare of the host by maintaining a healthier balance of intestinal microbiota, which provides a defensive barrier against colonization of harmful bacteria and stimulates the immune system [146-148]. In this study, the addition of three probiotics significantly reduced the increased abundance of pathogenic bacteria Aeromonas caused by pellet-feed feeding, which may be achieved through the direct competition of probiotics on the abundance of pathogenic bacteria and indirect regulation of host immunity. According to reports, lactic acid bacteria inhibit the growth of harmful bacteria by producing antimicrobial compounds and competing for nutrients and attachment sites $[41,149]$. The present result agrees with earlier findings where a similar decrease in pathogenic bacteria (Aeromonas sp. and Pseudomonas sp.) was reported in giant freshwater prawn (Macrobrachium rosenbergii) feeding with a diet supplemented with L. plantarum [150]. This result is also consistent with the early discovery which reported that L. rhamnosus micro-granules administered for 30 days to tilapia larvae could significantly reduce the proportion of potentially pathogenic bacteria [38]. In addition, C. butyricum treatment reversed the increased abundance of intestinal pathogens in mice induced by severe acute pancreatitis and intra-abdominal hypertension [73]. All this indicates that these three probiotics can inhibit the abundance of harmful intestinal bacteria Aeromonas in the in vivo model resulting from direct competition between probiotics and pathogenic bacteria and host immunity regulation.

The intestine is the leading site of nutrient absorption, and the health of villi is a crucial factor influencing nutrient absorption. Consistent with the description of Wu et al. on the histological and histochemical characterization of mandarin fish tissues and organs, in our study, mandarin fish fed with live bait showed a conventional histological pattern of intestinal tissue [151]. In contrast, histological changes were detected in mandarin fish fed with pellet feed. Compared to mandarin fish fed on the live feed, the thickness of the foregut basement membrane in pellet feed-fed mandarin fish was significantly reduced, with similar results in other fish $[88,152,153]$. In addition, our results indicated that dietary supplement of L. plantarum, L. rhamnosus and C. butyricum enhanced the intestinal health development in mandarin fish by increasing the height of intestinal villi and the thickness of foregut basement membrane. Similarly, L. plantarum favorably recovered the cyclophosphamide-induced abnormal intestinal morphology in mice by improving the villus height [154]. Pangasius catfish (Pangasius bocourti) fed a diet supplemented with $L$. plantarum for 90 days exhibited a greater villus height in all intestines, with significant differences in the proximal intestine [155]. Wang et al. reported that $C$. butyricum increased the jejunal villus length and jejunal villus height to crypt depth ratio, while they decreased the jejunal crypt depth compared with those of the control and protected the intestinal villi morphology in a piglet model [114]. According to Sewaka et al., L. rhamnosus increased the villous height in the proximal, middle and distal parts of the intestine of juvenile red tilapia (Oreochromis spp.) [37]. Moreover, Casas et al. reported that the intestinal villus height of weanling pigs tended to increase as the dose of C. butyricum increased in the diet [94]. Our findings indicate that the application of probiotics could effectively promote the intestinal 
health of mandarin fish fed with pellet feed, which may benefit from repair of the intestinal microbial barrier. At the same time, the promoting effect of probiotics on intestinal health may be one of the reasons for the improvement of survival rate of mandarin fish fed with pellet feed.

\section{Conclusions}

In summary, the present results confirmed that the application of L. plantarum, L. rhamnosus and C. butyricum could significantly improve the eating disorders of mandarin fish caused by pellet-feed feeding, which expressed as significantly increased POPFR and survival rate. All of these may be related to the ability of probiotics to regulate gut microbiota, activate immunity, boost appetite, improve antioxidant capacity and protect intestinal tissues. This study explores the problem of eating disorders in non-mammals and tried to solve the eating disorders caused by pellet-feed feeding of mandarin fish by regulating gut microbiota using probiotics. In this study, the influence of probiotics intervention on eating disorders and its mechanism were studied using mandarin fish fed with pellet feed as a model. Due to the complex interactions between the gut microbiota, immune system, appetite and oxidative stress, the causal relationship between them needs to be further investigated. The conversion of pellet feed for mandarin fish has always been considered a global problem, and this study provides a new train of thought. More solutions, such as the application of other probiotics, prebiotics or immunostimulants, are worth investigating.

Author Contributions: Conceptualization, X.C. and G.L.; methodology, X.C.; software, X.C.; validation, X.C., H.Y. and S.L.; formal analysis, X.C. and Y.Z.; investigation, X.C. and Y.S.; resources, X.C. and X.L.; data curation, X.C. and S.B.; writing-original draft preparation, X.C.; writing-review and editing, X.C. and H.L.; visualization, X.C. and Z.Z.; supervision, X.C.; project administration, X.C.; funding acquisition, G.L. All authors have read and agreed to the published version of the manuscript.

Funding: This research was funded by the Guangdong Province Key Field R\&D Program Project, grant number 20200202; Guangdong Basic and Applied Basic Research Foundation, grant number 2019B1515120072; the State Guides the Local Science and Technology Development Special Funding Project in 2021 (Construction of Germ plasm Resource Bank of Micropterus salmoides and Siniperca chuatsi in Guangdong Province); the Research in Spreading and Breeding Feedstuff of a New Breed of Siniperca chuatsi $\times$ Siniperca scherzeri, grant number Yuenong 2019A2.

Institutional Review Board Statement: The study was conducted according to the guidelines of the Declaration of Helsinki, and approved by the Institutional Animal Care and Use Committee of Sun Yat-sen University (SYSU-IACUC-2020-B0423).

Informed Consent Statement: Not applicable.

Data Availability Statement: The data presented in this study are available on request from the corresponding author.

Acknowledgments: The authors gratefully acknowledge the aquaculture farm (Foshan, Guangdong) for providing fry and breeding help. The author would like to thank the laboratory instrument management teacher for help in using the instrument.

Conflicts of Interest: The authors declare no conflict of interest.

\section{References}

1. Cooper, Z.; Grave, R.D. Eating Disorders: Transdiagnostic Theory and Treatment. In The Science of Cognitive Behavioral Therapy; Academic Press: Cambridge, MA, USA, 2017; pp. 337-357.

2. Smink, F.R.E.; Van Hoeken, D.; Hoek, H.W. Epidemiology of Eating Disorders: Incidence, Prevalence and Mortality Rates. Curr. Psychiatry Rep. 2012, 14, 406-414. [CrossRef]

3. Hoek, H.W.; Van Hoeken, D. Review of the prevalence and incidence of eating disorders. Int. J. Eat. Disord. 2003, 34, $383-396$. [CrossRef] [PubMed]

4. Hay, P. Current approach to eating disorders: A clinical update. Intern. Med. J. 2020, 50, 24-29. [CrossRef]

5. Johnson, J.G.; Cohen, P.; Kasen, S.; Brook, J.S. Eating Disorders during Adolescence and the Risk for Physical and Mental Disorders During Early Adulthood. Arch. Gen. Psychiatry 2002, 59, 545-552. [CrossRef] [PubMed] 
6. Clouard, C.; Meunier-Salaün, M.; Val-Laillet, D. Food preferences and aversions in human health and nutrition: How can pigs help the biomedical research? Animal 2012, 6, 118-136. [CrossRef] [PubMed]

7. Yanovski, S. Sugar and fat: Cravings and aversions. J. Nutr. 2003, 133, 835S-837S. [CrossRef]

8. He, S.; You, J.-J.; Liang, X.-F.; Zhang, Z.-L.; Zhang, Y.-P. Transcriptome sequencing and metabolome analysis of food habits domestication from live prey fish to artificial diets in mandarin fish (Siniperca chuatsi). BMC Genom. 2021, 22, 1-12. [CrossRef]

9. Ventura, A.K.; Worobey, J. Early Influences on the Development of Food Preferences. Curr. Biol. 2013, 23, R401-R408. [CrossRef]

10. Chen, K.; Zhang, Z.; Li, J.; Xie, S.; Shi, L.-J.; He, Y.-H.; Liang, X.-F.; Zhu, Q.-S.; He, S. Different regulation of branched-chain amino acid on food intake by TOR signaling in Chinese perch (Siniperca chuatsi). Aquaculture 2021, 530, 735792. [CrossRef]

11. Cota, D.; Yoon, A.; Peng, G.; Brandenburg, Y.; Zollo, O.; Xu, W.; Rego, E.; Ruggero, D. Hypothalamic mTOR Signaling Regulates Food Intake. Science 2006, 312, 927-930. [CrossRef]

12. Valassi, E.; Scacchi, M.; Cavagnini, F. Neuroendocrine control of food intake. Nutr. Metab. Cardiovasc. Dis. 2008, 18, 158-168. [CrossRef]

13. Sohn, J.-W. Network of hypothalamic neurons that control appetite. BMB Rep. 2015, 48, 229-233. [CrossRef]

14. Volkoff, H. The Neuroendocrine Regulation of Food Intake in Fish: A Review of Current Knowledge. Front. Neurosci. 2016, 10, 540. [CrossRef]

15. Gorissen, M.; Flik, G. Leptin in teleostean fish, towards the origins of leptin physiology. J. Chem. Neuroanat. 2014, 61-62, 200-206. [CrossRef]

16. Jönsson, E. The role of ghrelin in energy balance regulation in fish. Gen. Comp. Endocrinol. 2013, 187, 79-85. [CrossRef] [PubMed]

17. Clemente, J.C.; Ursell, L.K.; Parfrey, L.W.; Knight, R. The Impact of the Gut Microbiota on Human Health: An Integrative View. Cell 2012, 148, 1258-1270. [CrossRef]

18. Subramanian, S.; Blanton, L.V.; Frese, S.A.; Charbonneau, M.; Mills, D.A.; Gordon, J.I. Cultivating Healthy Growth and Nutrition through the Gut Microbiota. Cell 2015, 161, 36-48. [CrossRef]

19. Vuong, H.E.; Yano, J.M.; Fung, T.C.; Hsiao, E.Y. The Microbiome and Host Behavior. Annu. Rev. Neurosci. 2017, 40, 21-49. [CrossRef] [PubMed]

20. Cryan, J.F.; O’Riordan, K.J.; Cowan, C.S.M.; Sandhu, K.V.; Bastiaanssen, T.F.S.; Boehme, M.; Codagnone, M.G.; Cussotto, S.; Fulling, C.; Golubeva, A.V.; et al. The Microbiota-Gut-Brain Axis. Physiol. Rev. 2019, 99, 1877-2013. [CrossRef] [PubMed]

21. Martino, M.E.; Ma, D.; Leulier, F. Microbial influence on Drosophila biology. Curr. Opin. Microbiol. 2017, 38, 165-170. [CrossRef] [PubMed]

22. Ezra-Nevo, G.; Henriques, S.F.; Ribeiro, C. The diet-microbiome tango: How nutrients lead the gut brain axis. Curr. Opin. Neurobiol. 2020, 62, 122-132. [CrossRef] [PubMed]

23. Vijay-Kumar, M.; Aitken, J.D.; Carvalho, F.A.; Cullender, T.C.; Mwangi, S.; Srinivasan, S.; Sitaraman, S.V.; Knight, R.; Ley, R.E.; Gewirtz, A.T. Metabolic Syndrome and Altered Gut Microbiota in Mice Lacking Toll-Like Receptor 5. Science 2010, 328, $228-231$. [CrossRef]

24. Breton, J.; Tennoune, N.; Lucas, N.; Francois, M.; Legrand, R.; Jacquemot, J.; Goichon, A.; Guérin, C.; Peltier, J.; Pestel-Caron, M.; et al. Gut Commensal E. coli Proteins Activate Host Satiety Pathways following Nutrient-Induced Bacterial Growth. Cell Metab. 2016, 23, 324-334. [CrossRef] [PubMed]

25. Leitão-Gonçalves, R.; Santos, Z.; Francisco, A.P.; Fioreze, G.T.; Anjos, M.; Baltazar, C.; Elias, A.P.; Itskov, P.; Piper, M.; Ribeiro, C. Commensal bacteria and essential amino acids control food choice behavior and reproduction. PLoS Biol. 2017, 15, e2000862. [CrossRef]

26. Van De Wouw, M.; Schellekens, H.; Dinan, T.G.; Cryan, J.F. Microbiota-Gut-Brain Axis: Modulator of Host Metabolism and Appetite. J. Nutr. 2017, 147, 727-745. [CrossRef]

27. De Almada, C.N.; Almada, C.N.; Martinez, R.C.; Sant'Ana, A.S. Paraprobiotics: Evidences on their ability to modify biological responses, inactivation methods and perspectives on their application in foods. Trends Food Sci. Technol. 2016, 58, 96-114. [CrossRef]

28. Echeng, G.; Ehao, H.; Exie, S.; Ewang, X.; Edai, M.; Ehuang, L.; Eyuan, Z.-H. Antibiotic alternatives: The substitution of antibiotics in animal husbandry? Front. Microbiol. 2014, 5, 217. [CrossRef]

29. Watts, M.; Munday, B.L.; Burke, C.M. Immune responses of teleost fish. Aust. Veter J. 2001, 79, 570-574. [CrossRef]

30. Gatesoupe, F. The use of probiotics in aquaculture. Aquaculture 1999, 180, 147-165. [CrossRef]

31. Chauhan, A.; Singh, R. Probiotics in aquaculture: A promising emerging alternative approach. Symbiosis 2019, 77, 99-113. [CrossRef]

32. Ringø, E. Probiotics in shellfish aquaculture. Aquac. Fish. 2020, 5, 1-27. [CrossRef]

33. Balcázar, J.L.; de Blas, I.; Ruiz-Zarzuela, I.; Cunningham, D.; Vendrell, D.; Múzquiz, J.L. The role of probiotics in aquaculture. Veter Microbiol. 2006, 114, 173-186. [CrossRef]

34. Wang, L.; Jian, Y.; Liu, Q.; Li, F.; Chang, L. Electromagnetohydrodynamic flow and heat transfer of third grade fluids between two micro-parallel plates. Colloids Surf. A Physicochem. Eng. Asp. 2016, 494, 87-94. [CrossRef]

35. Van Nguyen, N.; Onoda, S.; Van Khanh, T.; Hai, P.D.; Trung, N.T.; Hoang, L.; Koshio, S. Evaluation of dietary Heat-killed Lactobacillus plantarum strain L-137 supplementation on growth performance, immunity and stress resistance of Nile tilapia (Oreochromis niloticus). Aquaculture 2019, 498, 371-379. [CrossRef] 
36. Hooshyar, Y.; Kenari, A.A.; Paknejad, H.; Gandomi, H. Effects of Lactobacillus rhamnosus ATCC 7469 on Different Parameters Related to Health Status of Rainbow Trout (Oncorhynchus mykiss) and the Protection Against Yersinia ruckeri. Probiotics Antimicrob. Proteins 2020, 12, 1370-1384. [CrossRef]

37. Sewaka, M.; Trullas, C.; Chotiko, A.; Rodkhum, C.; Chansue, N.; Boonanuntanasarn, S.; Pirarat, N. Efficacy of synbiotic Jerusalem artichoke and Lactobacillus rhamnosus GG-supplemented diets on growth performance, serum biochemical parameters, intestinal morphology, immune parameters and protection against Aeromonas veronii in juvenile red tilapia (Oreochromis spp.). Fish Shellfish Immunol. 2019, 86, 260-268. [CrossRef] [PubMed]

38. Giorgia, G.; Elia, C.; Andrea, P.; Cinzia, C.; Stefania, S.; Ana, R.; Daniel, M.L.; Ike, O.; Oliana, C. Effects of Lactogen 13, a New Probiotic Preparation, on Gut Microbiota and Endocrine Signals Controlling Growth and Appetite of Oreochromis niloticus Juveniles. Microb. Ecol. 2018, 76, 1063-1074. [CrossRef] [PubMed]

39. Poolsawat, L.; Li, X.; He, M.; Ji, D.; Leng, X.J.A.N. Clostridium butyricum as probiotic for promoting growth performance, feed utilization, gut health and microbiota community of tilapia (Oreochromis niloticus $\times$ O. aureus). Aquac. Nutr. 2020, 26, 657-670. [CrossRef]

40. Zhang, M.; Dong, B.; Lai, X.; Chen, Z.; Hou, L.; Shu, R.; Huang, Y.; Shu, H. Effects of Clostridium butyricum on growth, digestive enzyme activity, antioxidant capacity and gut microbiota in farmed tilapia (Oreochromis niloticus). Aquac. Res. 2021, 52, 1573-1584. [CrossRef]

41. Balcázar, J.L.; Vendrell, D.; de Blas, I.; Ruiz-Zarzuela, I.; Muzquiz, J.L.; Girones, O. Characterization of probiotic properties of lactic acid bacteria isolated from intestinal microbiota of fish. Aquaculture 2008, 278, 188-191. [CrossRef]

42. Henriques, S.F.; Dhakan, D.B.; Serra, L.; Francisco, A.P.; Carvalho-Santos, Z.; Baltazar, C.; Elias, A.P.; Anjos, M.; Zhang, T.; Maddocks, O.D.K.; et al. Metabolic cross-feeding in imbalanced diets allows gut microbes to improve reproduction and alter host behaviour. Nat. Commun. 2020, 11, 4236. [CrossRef] [PubMed]

43. Lash, B.W.; Mysliwiec, T.H.; Gourama, H. Detection and partial characterization of a broad-range bacteriocin produced by Lactobacillus plantarum (ATCC 8014). Food Microbiol. 2005, 22, 199-204. [CrossRef]

44. Giri, S.S.; Sukumaran, V.; Oviya, M. Potential probiotic Lactobacillus plantarum VSG3 improves the growth, immunity, and disease resistance of tropical freshwater fish, Labeo rohita. Fish Shellfish. Immunol. 2013, 34, 660-666. [CrossRef] [PubMed]

45. Parthasarathy, R.; Ravi, D. Probiotic bacteria as growth promoter and biocontrol agent against Aeromonas hydrophila in Catla catla (Hamilton, 1822). Indian J. Fish. 2011, 58, 87-93.

46. Son, V.M.; Chang, C.-C.; Wu, M.-C.; Guu, Y.-K.; Chiu, C.-H.; Cheng, W. Dietary administration of the probiotic, Lactobacillus plantarum, enhanced the growth, innate immune responses, and disease resistance of the grouper Epinephelus coioides. Fish Shellfish Immunol. 2009, 26, 691-698. [CrossRef]

47. Jatobá, A.; Vieira, F.D.N.; Buglione-Neto, C.C.; Mouriño', J.L.P.; Silva, B.C.; Seiftter, W.Q.; Andreatta, E.R. Diet supplemented with probiotic for Nile tilapia in polyculture system with marine shrimp. Fish Physiol. Biochem. 2011, 37, 725-732. [CrossRef]

48. Uma, A.; Abraham, T.J.; Sundararaj, V. Effect of a probiotic bacterium, Lactobacillus plantarum on disease resistance of Penaeus indicus larvae. Indian J. Fish. 1999, 46, 367-373.

49. Kongnum, K.; Hongpattarakere, T. Effect of Lactobacillus plantarum isolated from digestive tract of wild shrimp on growth and survival of white shrimp (Litopenaeus vannamei) challenged with Vibrio harveyi. Fish Shellfish Immunol. 2012, 32, 170-177. [CrossRef]

50. Chiu, C.-H.; Guu, Y.-K.; Liu, C.-H.; Pan, T.-M.; Cheng, W. Immune responses and gene expression in white shrimp, Litopenaeus vannamei, induced by Lactobacillus plantarum. Fish Shellfish Immunol. 2007, 23, 364-377. [CrossRef]

51. Vieira, F.N.; Buglione, C.C.; Mouriño, J.P.L.; Jatobá, A.; Martins, M.L.; Schleder, D.D.; Andreatta, E.R.; Barraco, M.A.; Vinatea, L.A. Effect of probiotic supplemented diet on marine shrimp survival after challenge with Vibrio harveyi. Arquivo Brasileiro de Medicina Veterinária e Zootecnia 2010, 62, 631-638. [CrossRef]

52. Iman, M.K.A.; Wafaa, T.A.; Elham, S.A.; Mohammad, M.N.A.; El-Shafei, K.; Osama, M.S.; Gamal, A.I.; Zeinab, I.S.; El-Sayed, H.S. Evaluation of Lactobacillus plantarum as a probiotic in aquaculture: Emphasis on growth performance and innate immunity. $J$. Appl. Sci. Res. 2013, 9, 572-582.

53. Bravo, J.A.; Forsythe, P.; Chew, M.V.; Escaravage, E.; Savignac, H.M.; Dinan, T.G.; Bienenstock, J.; Cryan, J.F. Ingestion of Lactobacillus strain regulates emotional behavior and central GABA receptor expression in a mouse via the vagus nerve. Proc. Natl. Acad. Sci. USA 2011, 108, 16050-16055. [CrossRef]

54. Liang, S.; Wang, T.; Hu, X.; Luo, J.; Li, W.; Wu, X.; Duan, Y.; Jin, F. Administration of Lactobacillus helveticus NS8 improves behavioral, cognitive, and biochemical aberrations caused by chronic restraint stress. Neuroscience 2015, 310, 561-577. [CrossRef]

55. Janik, R.; Thomason, L.A.; Stanisz, A.M.; Forsythe, P.; Bienenstock, J.; Stanisz, G.J. Magnetic resonance spectroscopy reveals oral Lactobacillus promotion of increases in brain GABA, N-acetyl aspartate and glutamate. NeuroImage 2016, 125, 988-995. [CrossRef] [PubMed]

56. Lyte, M. Probiotics function mechanistically as delivery vehicles for neuroactive compounds: Microbial endocrinology in the design and use of probiotics. BioEssays 2011, 33, 574-581. [CrossRef] [PubMed]

57. Lyte, M. Microbial endocrinology. Gut Microbes 2014, 5, 381-389. [CrossRef] [PubMed]

58. Kong, Q.; He, G.-Q.; Jia, J.-L.; Zhu, Q.-L.; Ruan, H. Oral Administration of Clostridium butyricum for Modulating Gastrointestinal Microflora in Mice. Curr. Microbiol. 2010, 62, 512-517. [CrossRef] 
59. Yang, C.; Cao, G.; Xiao, Y.; Chen, A.; Liu, T.; Zhou, L.; Zhang, L.; Ferket, P. Effects of Clostridium butyricum on Growth Performance, Nitrogen Metabolism, Intestinal Morphology and Cecal Microflora in Broiler Chickens. J. Anim. Veter Adv. 2012, 11, 2665-2671. [CrossRef]

60. Juan, Z.; Chun, W.; Zhao-Ling, S.; Ming-Hua, Z.; Hai-Xia, W.; Meng-Yun, L.; Jian-Qiong, H.; Yue-Jie, Z.; Xin, S. Oral administration of Clostridium butyricum CGMCC0313-1 reduces ovalbumin-induced allergic airway inflammation in mice. Respirology 2017, 22, 898-904. [CrossRef]

61. Yang, C.M.; Cao, G.T.; Ferket, P.; Liu, T.T.; Zhou, L.; Zhang, L.; Xiao, Y.P.; Chen, A.G. Effects of probiotic, Clostridium butyricum, on growth performance, immune function, and cecal microflora in broiler chickens. Poult. Sci. 2012, 91, 2121-2129. [CrossRef]

62. Chen, L.; Li, S.; Zheng, J.; Li, W.; Jiang, X.; Zhao, X.; Wu, D. Effects of dietary Clostridium butyricum supplementation on growth performance,intestinal development, and immune response of weaned piglets challenged with lipopolysaccharide. J. Anim. Sci. Biotechnol. 2018, 9, 1-14. [CrossRef]

63. Sisson, G.; Ayis, S.; Sherwood, R.A.; Bjarnason, I. Randomised clinical trial: A liquid multi-strain probiotic vs. placebo in the irritable bowel syndrome-A 12 week double-blind study. Aliment. Pharmacol. Ther. 2014, 40, 51-62. [CrossRef] [PubMed]

64. Sun, Y.-Y.; Li, M.; Li, Y.-Y.; Li, L.-X.; Zhai, W.-Z.; Wang, P.; Yang, X.-X.; Gu, X.; Song, L.-J.; Li, Z.; et al. The effect of Clostridium butyricum on symptoms and fecal microbiota in diarrhea-dominant irritable bowel syndrome: A randomized, double-blind, placebo-controlled trial. Sci. Rep. 2018, 8, 2964. [CrossRef] [PubMed]

65. Hudson, L.E.; Anderson, S.E.; Corbett, A.H.; Lamb, T.J. Gleaning Insights from Fecal Microbiota Transplantation and Probiotic Studies for the Rational Design of Combination Microbial Therapies. Clin. Microbiol. Rev. 2017, 30, 191-231. [CrossRef] [PubMed]

66. Lv, L.; Liang, X.F.; Huang, K.; He, S. Effect of agmatine on food intake in mandarin fish (Siniperca chuatsi). Fish Physiol. Biochem. 2019, 45, 1709-1716. [CrossRef]

67. Liang, X.F.; Oku, H.; Ogata, H.Y.; Liu, J.; He, X. Weaning Chinese perch Siniperca chuatsi (Basilewsky) onto artificial diets based upon its specific sensory modality in feeding. Aquac. Res. 2001, 32, 76-82. [CrossRef]

68. Zhang, X.; Xiang, J.; Yin, M. The influences of temperature on the feeding,growth and development oflarval siniperca chuatsi. J. Fish. China 1999, 1, 91-94.

69. Dou, Y.; He, S.; Liang, X.-F.; Cai, W.; Wang, J.; Shi, L.; Li, J. Memory Function in Feeding Habit Transformation of Mandarin Fish (Siniperca chuatsi). Int. J. Mol. Sci. 2018, 19, 1254. [CrossRef] [PubMed]

70. Li, L.; Fang, J.; Liang, X.; Alam, M.S.; Liu, L.; Yuan, X. Effect of feeding stimulants on growth performance, feed intake and appetite regulation of mandarin fish,Siniperca chuatsi. Aquac. Res. 2019, 50, 3684-3691. [CrossRef]

71. Cao, G.; Tao, F.; Hu, Y.; Li, Z.; Zhang, Y.; Deng, B.; Zhan, X. Positive effects of a Clostridium butyricum-based compound probiotic on growth performance, immune responses, intestinal morphology, hypothalamic neurotransmitters, and colonic microbiota in weaned piglets. Food Funct. 2019, 10, 2926-2934. [CrossRef] [PubMed]

72. Zheng, X.; Duan, Y.; Dong, H.; Zhang, J. Effects of Dietary Lactobacillus plantarum on Growth Performance, Digestive Enzymes and Gut Morphology of Litopenaeus vannamei. Probiotics Antimicrob. Proteins 2018, 10, 504-510. [CrossRef] [PubMed]

73. Zhao, H.-B.; Jia, L.; Yan, Q.-Q.; Deng, Q.; Wei, B. Effect of Clostridium butyricum and Butyrate on Intestinal Barrier Functions: Study of a Rat Model of Severe Acute Pancreatitis With Intra-Abdominal Hypertension. Front. Physiol. 2020, 11, 561061. [CrossRef]

74. Ukeda, H. Novel assay methods of enzyme superoxide dismutase (SOD). Nippon Nogeikagaku Kaishi J. Japan Soc. Biosci. Biotechnol. Agrochem. 2001, 75, 562-565.

75. Buege, J.A.; Aust, S.D. Microsomal lipid peroxidation. Methods Enzymol. 1978, 52, 302-310. [CrossRef] [PubMed]

76. Nebot, C.; Moutet, M.; Huet, P.; Xu, J.; Yadan, J.; Chaudière, J. Spectrophotometric Assay of Superoxide Dismutase Activity Based on the Activated Autoxidation of a Tetracyclic Catechol. Anal. Biochem. 1993, 214, 442-451. [CrossRef]

77. Reiners, J.J.; Thai, G.; Rupp, T.; Cantu, A.R. Assessment of the antioxidant/prooxidant status of murine skin following topical treatment with 12- O -tetradecanoylphorbol-13-acetate and throughout the ontogeny of skin cancer. Part I: Quantitation of superoxide dismutase, catalase, glutathione peroxidase and xanthine oxidase. Carcinogenesis 1991, 12, 2337-2343. [CrossRef] [PubMed]

78. Schmittgen, T.D.; Livak, K.J. Analyzing real-time PCR data by the comparative $\mathrm{C}_{\mathrm{T}}$ method. Nat. Protoc. 2008, 3, 1101-1108. [CrossRef]

79. Magoč, T.; Salzberg, S.L. FLASH: Fast Length Adjustment of Short Reads to Improve Genome Assemblies. Bioinformatics 2011, 27, 2957-2963. [CrossRef] [PubMed]

80. Edgar, R.C.; Haas, B.J.; Bioinformatics, C.J. UCHIME improves sensitivity and speed of chimera detection. Bioinformatics 2011, 27, 2194-2200. [CrossRef] [PubMed]

81. Caporaso, J.G.; Kuczynski, J.; Stombaugh, J.; Bittinger, K.; Bushman, F.D.; Costello, E.K.; Fierer, N.; Peña, A.G.; Goodrich, J.K.; Gordon, J.I.; et al. QIIME Allows Analysis of High-Throughput Community Sequencing data. Nat. Methods 2010, 7, $335-336$. [CrossRef]

82. Edgar, R.C. UPARSE: Highly accurate OTU sequences from microbial amplicon reads. Nat. Methods 2013, 10, 996-998. [CrossRef]

83. Segata, N.; Izard, J.; Waldron, L.; Gevers, D.; Miropolsky, L.; Garrett, W.S.; Huttenhower, C. Metagenomic biomarker discovery and explanation. Genome Biol. 2011, 12, R60. [CrossRef] [PubMed]

84. Aßhauer, K.P.; Wemheuer, B.; Daniel, R.; Meinicke, P. Tax4Fun: Predicting functional profiles from metagenomic 16S rRNA data: Fig. 1. Bioinformatics 2015, 31, 2882-2884. [CrossRef] 
85. Seitz, J.; Trinh, S.; Herpertz-Dahlmann, B. The Microbiome and Eating Disorders. Psychiatr. Clin. N. Am. 2019, 42, 93-103. [CrossRef] [PubMed]

86. Dinan, T.G.; Cryan, J.F. Melancholic microbes: A link between gut microbiota and depression? Neurogastroenterol. Motil. 2013, 25, 713-719. [CrossRef]

87. Chen, X.; Yi, H.; Liu, S.; Zhang, Y.; Su, Y.; Liu, X.; Bi, S.; Lai, H.; Zeng, Z.; Li, G. Promotion of pellet-feed feeding in mandarin fish (Siniperca chuatsi) by Bdellovibrio bacteriovorus is influenced by immune and intestinal flora. Aquaculture 2021, 542,736864 . [CrossRef]

88. Fernandez-Diaz, C.; Kopecka, J.; Cañavate, J.P.; Sarasquete, C.; Sole, M. Variations on development and stress defences in Solea senegalensis larvae fed on live and microencapsulated diets. Aquaculture 2006, 251, 573-584. [CrossRef]

89. Dawood, M.A. Nutritional immunity of fish intestines: Important insights for sustainable aquaculture. Rev. Aquac. 2021, 13, 642-663. [CrossRef]

90. Yúfera, M.; Fernandez-Diaz, C.; Pascual, E. Food microparticles for larval fish prepared by internal gelation. Aquaculture 2005, 248, 253-262. [CrossRef]

91. Pérez-Sánchez, T.; Balcazar, J.L.; Merrifield, D.; Carnevali, O.; Gioacchini, G.; de Blas, I.; Ruiz-Zarzuela, I. Expression of immunerelated genes in rainbow trout (Oncorhynchus mykiss) induced by probiotic bacteria during Lactococcus garvieae infection. Fish Shellfish Immunol. 2011, 31, 196-201. [CrossRef]

92. Duan, Y.; Zhang, J.; Huang, J.; Jiang, S. Effects of Dietary Clostridium butyricum on the Growth, Digestive Enzyme Activity, Antioxidant Capacity, and Resistance to Nitrite Stress of Penaeus monodon. Probiotics Antimicrob. Proteins 2018, 11, 938-945. [CrossRef] [PubMed]

93. Oliva-Teles, A. Nutrition and health of aquaculture fish. J. Fish Dis. 2012, 35, 83-108. [CrossRef] [PubMed]

94. A Casas, G.; Blavi, L.; Cross, T.-W.L.; Lee, A.H.; Swanson, K.; Stein, H.H. Inclusion of the direct-fed microbial Clostridium butyricum in diets for weanling pigs increases growth performance and tends to increase villus height and crypt depth, but does not change intestinal microbial abundance. J. Anim. Sci. 2020, 98. [CrossRef]

95. Zhang, F.; Li, Y.; Wang, X.; Wang, S.; Bi, D. The Impact ofLactobacillus plantarumon the Gut Microbiota of Mice with DSS-Induced Colitis. BioMed Res. Int. 2019, 2019, 1-10. [CrossRef]

96. He, S.; Liang, X.F.; Sun, J.; Li, L.; Yu, Y.; Huang, W.; Qu, C.M.; Cao, L.; Bai, X.L.; Tao, Y. Insights into food preference in hybrid F1 of Siniperca chuatsi $(+) \times$ Siniperca scherzeri $\left({ }^{7}\right)$ mandarin fish through transcriptome analysis. BMC Genom. 2013, 14, 1-11. [CrossRef] [PubMed]

97. Biochemistry, H.V.J.C.; Molecular, P.P.A.; Physiology, I. The role of neuropeptide Y, orexins, cocaine and amphetamine-related transcript, cholecystokinin, amylin and leptin in the regulation of feeding in fish. Biochem. Physiol. Part A Mol. Integr. Physiol. 2006, 144, 325-331.

98. Rui, L. Brain regulation of energy balance and body weight. Rev. Endocr. Metab. Disord. 2013, 14, 387-407. [CrossRef]

99. Crespo, C.S.; Cachero, A.P.; Jimã Nez, L.P.; Barrios, V.; Ferreiro, E.A. Peptides and Food Intake. Front. Endocrinol. 2014, 5, 58. [CrossRef]

100. Volkoff, H.; Canosa, L.; Unniappan, S.; Cerdá-Reverter, J.; Bernier, N.; Kelly, S.; Peter, R. Neuropeptides and the control of food intake in fish. Gen. Comp. Endocrinol. 2005, 142, 3-19. [CrossRef]

101. Holzer, P.; Reichmann, F.; Farzi, A. Neuropeptide Y, peptide YY and pancreatic polypeptide in the gut-brain axis. Neuropeptides 2012, 46, 261-274. [CrossRef]

102. Cerdá-Reverter, J.M.; Agulleiro, M.J.; Guillot, R.; Sánchez, E.; Ceinos, R.M.; Rotllant, J. Fish melanocortin system. Eur. J. Pharmacol. 2011, 660, 53-60. [CrossRef]

103. Riley, L.G.; Fox, B.K.; Kaiya, H.; Hirano, T.; Grau, E.G. Long-term treatment of ghrelin stimulates feeding, fat deposition, and alters the GH/IGF-I axis in the tilapia, Oreochromis mossambicus. Gen. Comp. Endocrinol. 2005, 142, 234-240. [CrossRef] [PubMed]

104. Kaiya, H.; Miyazato, M.; Kangawa, K.; Peter, R.E.; Unniappan, S. Ghrelin: A multifunctional hormone in non-mammalian vertebrates. Comp. Biochem. Physiol. Part A Mol. Integr. Physiol. 2008, 149, 109-128. [CrossRef]

105. Tan, Y.-Y.; Ji, Z.-L.; Zhao, G.; Jiang, J.-R.; Wang, N.; Wang, J.-M. Decreased SCF/c-kit signaling pathway contributes to loss of interstitial cells of Cajal in gallstone disease. Int. J. Clin. Exp. Med. 2014, 7, 4099-4106. [PubMed]

106. ThanThan, S.; Mekaru, C.; Seki, N.; Hidaka, K.; Ueno, A.; ThidarMyint, H.; Kuwayama, H. Endogenous ghrelin released in response to endothelin stimulates growth hormone secretion in cattle. Domest. Anim. Endocrinol. 2010, 38, 1-12. [CrossRef] [PubMed]

107. Won, E.T.; Douros, J.D.; Hurt, D.A.; Borski, R.J. Leptin stimulates hepatic growth hormone receptor and insulin-like growth factor gene expression in a teleost fish, the hybrid striped bass. Gen. Comp. Endocrinol. 2016, 229, 84-91. [CrossRef]

108. Browning, K.N.; Verheijden, S.; Boeckxstaens, G.E. The Vagus Nerve in Appetite Regulation, Mood, and Intestinal Inflammation. Gastroenterology 2017, 152, 730-744. [CrossRef]

109. Caricilli, A. Intestinal barrier: A gentlemen's agreement between microbiota and immunity. World J. Gastrointest. Pathophysiol. 2014, 5, 18. [CrossRef]

110. Uribe, C.; Folch, H.; Enriquez, R.; Moran, G. Innate and adaptive immunity in teleost fish: A review. Veterinární Medicína 2011, 56, 486-503. [CrossRef] 
111. Singh, P.B.; Singh, V. Cypermethrin induced histological changes in gonadotrophic cells, liver, gonads, plasma levels of estradiol$17 \beta$ and 11-ketotestosterone, and sperm motility in Heteropneustes fossilis (Bloch). Chemosphere 2008, 72, 422-431. [CrossRef] [PubMed]

112. Dominguez, M.; Takemura, A.; Tsuchiya, M.; Nakamura, S. Impact of different environmental factors on the circulating immunoglobulin levels in the Nile tilapia, Oreochromis niloticus. Aquaculture 2004, 241, 491-500. [CrossRef]

113. Zhai, Q.; Wang, H.; Tian, F.; Zhao, J.; Zhang, H.; Chen, W. Dietary Lactobacillus plantarum supplementation decreases tissue lead accumulation and alleviates lead toxicity in Nile tilapia (Oreochromis niloticus). Aquac. Res. 2017, 48, 5094-5103. [CrossRef]

114. Wang, K.; Cao, G.; Zhang, H.; Li, Q.; Yang, C. Effects of Clostridium butyricum and Enterococcus faecalis on growth performance, immune function, intestinal morphology, volatile fatty acids, and intestinal flora in a piglet model. Food Funct. 2019, 10, 7844-7854 [CrossRef] [PubMed]

115. Liao, X.D.; Ma, G.; Cai, J.; Fu, Y.; Yan, X.Y.; Wei, X.B.; Zhang, R.J. Effects ofClostridium butyricum on growth performance, antioxidation, and immune function of broilers. Poult. Sci. 2015, 94, 662-667. [CrossRef]

116. Jia, R.; Gu, Z.; He, Q.; Du, J.; Cao, L.; Jeney, G.; Xu, P.; Yin, G. Anti-oxidative, anti-inflammatory and hepatoprotective effects of Radix Bupleuri extract against oxidative damage in tilapia (Oreochromis niloticus) via Nrf2 and TLRs signaling pathway. Fish Shellfish Immunol. 2019, 93, 395-405. [CrossRef]

117. Dong, Y.; Tu, J.; Zhou, Y.; Zhou, X.H.; Xu, B.; Zhu, S.Y. Silybum marianum oil attenuates oxidative stress and ameliorates mitochondrial dysfunction in mice treated with D-galactose. Pharmacogn. Mag. 2014, 10, S92-S99. [CrossRef] [PubMed]

118. Chen, P.; Chen, F.; Zhou, B. Antioxidative, anti-inflammatory and anti-apoptotic effects of ellagic acid in liver and brain of rats treated by D-galactose. Sci. Rep. 2018, 8, 1-10. [CrossRef] [PubMed]

119. Li, Y.; Li, J.; Lu, J.; Li, Z.; Shi, S.; Liu, Z. Effects of live and artificial feeds on the growth, digestion, immunity and intestinal microflora of mandarin fish hybrid (Siniperca chuatsi $+\times$ Siniperca scherzeri o'). Aquac. Res. 2017, 48, 4479-4485. [CrossRef]

120. Peters, L.D.; Livingstone, D. Antioxidant enzyme activities in embryologic and early larval stages of turbot. J. Fish Biol. 1996, 49, 986-997. [CrossRef]

121. Mourente, G.; Tocher, D.; Diaz, E.; Grau, A.; Pastor, E. Relationships between antioxidants, antioxidant enzyme activities and lipid peroxidation products during early development in Dentex dentex eggs and larvae. Aquaculture 1999, 179, 309-324. [CrossRef]

122. Dandapat, J.; Chainy, G.B.; Rao, K.J. Lipid peroxidation and antioxidant defence status during larval development and metamorphosis of giant prawn, Macrobrachium rosenbergii. Comp. Biochem. Physiol. Part C Toxicol. Pharmacol. 2003, 135, 221-233. [CrossRef]

123. Rueda-Jasso, R.; Conceição, L.; Dias, J.; De Coen, W.; Gomes, E.; Rees, J.; Soares, F.; Dinis, M.T.; Sorgeloos, P. Effect of dietary non-protein energy levels on condition and oxidative status of Senegalese sole (Solea senegalensis) juveniles. Aquaculture 2004, 231, 417-433. [CrossRef]

124. Solé, M.; Potrykus, J.; Fernandez-Diaz, C.; Blasco, J. Variations on stress defences and metallothionein levels in the Senegal sole, Solea senegalensis, during early larval stages. Fish Physiol. Biochem. 2004, 30, 57-66. [CrossRef]

125. Liu, J.; Fu, Y.; Zhang, H.; Wang, J.; Zhu, J.; Wang, Y.; Guo, Y.; Wang, G.; Xu, T.; Chu, M.; et al. The hepatoprotective effect of the probiotic Clostridium butyricum against carbon tetrachloride-induced acute liver damage in mice. Food Funct. 2017, 8, 4042-4052. [CrossRef] [PubMed]

126. Alcock, J.; Maley, C.C.; Aktipis, C.A. Is eating behavior manipulated by the gastrointestinal microbiota? Evolutionary pressures and potential mechanisms. BioEssays 2014, 36, 940-949. [CrossRef] [PubMed]

127. Soriano, E.L.; Ramírez, D.T.; Araujo, D.R.; Gómez-Gil, B.; Castro, L.I.; Sánchez, C.G. Effect of temperature and dietary lipid proportion on gut microbiota in yellowtail kingfish Seriola lalandi juveniles. Aquaculture 2018, 497, 269-277. [CrossRef]

128. Dehler, C.E.; Secombes, C.J.; Martin, S.A.M. Environmental and physiological factors shape the gut microbiota of Atlantic salmon parr (Salmo salar L.). Aquaculture 2017, 467, 149-157. [CrossRef] [PubMed]

129. Benson, A.K.; Kelly, S.A.; Legge, R.; Ma, F.; Low, S.J.; Kim, J.; Zhang, M.; Oh, P.L.; Nehrenberg, D.; Hua, K.; et al. Individuality in gut microbiota composition is a complex polygenic trait shaped by multiple environmental and host genetic factors. Proc. Natl. Acad. Sci. USA 2010, 107, 18933-18938. [CrossRef] [PubMed]

130. Kovacs, A.; Ben-Jacob, N.; Tayem, H.; Halperin, E.; Iraqi, F.A.; Gophna, U. Genotype Is a Stronger Determinant than Sex of the Mouse Gut Microbiota. Microb. Ecol. 2010, 61, 423-428. [CrossRef]

131. Rawls, J.; Mahowald, M.A.; Ley, R.E.; Gordon, J.I. Reciprocal Gut Microbiota Transplants from Zebrafish and Mice to Germ-free Recipients Reveal Host Habitat Selection. Cell 2006, 127, 423-433. [CrossRef]

132. Arkoosh, M.R.; Clemons, E.; Kagley, A.N.; Stafford, C.; Glass, A.C.; Jacobson, K.; Reno, P.; Myers, M.S.; Casillas, E.; Loge, F.; et al. Survey of Pathogens in Juvenile SalmonOncorhynchusSpp. Migrating through Pacific Northwest Estuaries. J. Aquat. Anim. Heal. 2004, 16, 186-196. [CrossRef]

133. De Filippo, C.; Cavalieri, D.; Di Paola, M.; Ramazzotti, M.; Poullet, J.B.; Massart, S.; Collini, S.; Pieraccini, G.; Lionetti, P. Impact of diet in shaping gut microbiota revealed by a comparative study in children from Europe and rural Africa. Proc. Natl. Acad. Sci. USA 2010, 107, 14691-14696. [CrossRef] [PubMed]

134. A Koeth, R.; Wang, Z.; Levison, B.S.; A Buffa, J.; Org, E.; Sheehy, B.T.; Britt, E.B.; Fu, X.; Wu, Y.; Li, L.; et al. Intestinal microbiota metabolism of 1-carnitine, a nutrient in red meat, promotes atherosclerosis. Nat. Med. 2013, 19, 576-585. [CrossRef] [PubMed] 
135. Muegge, B.D.; Kuczynski, J.; Knights, D.; Clemente, J.C.; González, A.; Fontana, L.; Henrissat, B.; Knight, R.; Gordon, J.I. Diet Drives Convergence in Gut Microbiome Functions Across Mammalian Phylogeny and Within Humans. Science 2011, 332, 970-974. [CrossRef] [PubMed]

136. Bolnick, D.I.; Snowberg, L.K.; Hirsch, P.E.; Lauber, C.L.; Org, E.; Parks, B.; Lusis, A.J.; Knight, R.; Caporaso, J.G.; Svanbäck, R. Individual diet has sex-dependent effects on vertebrate gut microbiota. Nat. Commun. 2014, 5, 4500. [CrossRef]

137. David, L.A.; Maurice, C.F.; Carmody, R.N.; Gootenberg, D.; Button, J.E.; Wolfe, B.E.; Ling, A.V.; Devlin, A.S.; Varma, Y.; Fischbach, M.A.; et al. Diet rapidly and reproducibly alters the human gut microbiome. Nat. Cell Biol. 2014, 505, 559-563. [CrossRef]

138. Turnbaugh, P.J.; Hamady, M.; Yatsunenko, T.; Cantarel, B.L.; Duncan, A.; Ley, R.E.; Sogin, M.L.; Jones, W.J.; Roe, B.A.; Affourtit, J.P.; et al. A core gut microbiome in obese and lean twins. Nat. Cell Biol. 2008, 457, 480-484. [CrossRef]

139. Burns, A.R.; Stephens, W.Z.; Stagaman, K.; Wong, S.; Rawls, J.; Guillemin, K.; Bohannan, B.J. Contribution of neutral processes to the assembly of gut microbial communities in the zebrafish over host development. ISME J. 2016, 10, 655-664. [CrossRef]

140. Nayak, S.K. Role of gastrointestinal microbiota in fish. Aquac. Res. 2010, 41, 1553-1573. [CrossRef]

141. Sekirov, I.; Finlay, B.B. The role of the intestinal microbiota in enteric infection. J. Physiol. 2009, 587, 4159-4167. [CrossRef]

142. Olsen, R.E.; Sundell, K.; Mayhew, T.M.; Myklebust, R.; Ringø, E. Acute stress alters intestinal function of rainbow trout, Oncorhynchus mykiss (Walbaum). Aquaculture 2005, 250, 480-495. [CrossRef]

143. Gareau, M.G.; Wine, E.; Sherman, P.M. Early Life Stress Induces Both Acute and Chronic Colonic Barrier Dysfunction: Figure. NeoReviews 2009, 10, e191-e197. [CrossRef]

144. Stecher, B.; Robbiani, R.; Walker, A.W.; Westendorf, A.M.; Barthel, M.; Kremer, M.; Chaffron, S.; MacPherson, A.J.; Buer, J.; Parkhill, J.; et al. Salmonella enterica Serovar Typhimurium Exploits Inflammation to Compete with the Intestinal Microbiota. PLoS Biol. 2007, 5, e244-e2189. [CrossRef] [PubMed]

145. Dethlefsen, L.; Huse, S.; Sogin, M.L.; Relman, D.A. The Pervasive Effects of an Antibiotic on the Human Gut Microbiota, as Revealed by Deep 16S rRNA Sequencing. PLoS Biol. 2008, 6, e280. [CrossRef] [PubMed]

146. Cain, K.; Swan, C. Barrier function and immunology. In The Multifunctional Gut of Fish; Fish Physiology; Grosell, M., Farrell, A.P., Brauner, C.J., Eds.; Academic Press: Cambridge, MA, USA, 2010; Volume 30, pp. 111-134.

147. Gaggìa, F.; Mattarelli, P.; Biavati, B. Probiotics and prebiotics in animal feeding for safe food production. Int. J. Food Microbiol. 2010, 141, S15-S28. [CrossRef] [PubMed]

148. Gómez, G.D.; Balcázar, J.L. A review on the interactions between gut microbiota and innate immunity of fish: Table 1. FEMS Immunol. Med. Microbiol. 2008, 52, 145-154. [CrossRef]

149. Nikoskelainen, S.; Salminen, S.; Bylund, G.; Ouwehand, A.C. Characterization of the Properties of Human- and Dairy-Derived Probiotics for Prevention of Infectious Diseases in Fish. Appl. Environ. Microbiol. 2001, 67, 2430-2435. [CrossRef]

150. Dash, G.; Raman, R.P.; Prasad, K.P.; Makesh, M.; Pradeep, M.; Sen, S. Evaluation of Lactobacillus plantarum as feed supplement on host associated microflora, growth, feed efficiency, carcass biochemical composition and immune response of giant freshwater prawn, Macrobrachium rosenbergii (de Man, 1879). Aquaculture 2014, 432, 225-236. [CrossRef]

151. Xue-Feng, W.U.; Zhao, J.L.; Qian, Y.Z.; Chao, W. Histological Study of the Digestive System Organogenesis for the Mandarin Fish, Siniperca chuatsi. Zool. Res. 2007, 28, 511-518.

152. Yúfera, M.; Pascual, E.; Fernandez-Diaz, C. A highly efficient microencapsulated food for rearing early larvae of marine fish. Aquaculture 1999, 177, 249-256. [CrossRef]

153. Olsen, A.I.; Attramadal, Y.; Reitan, K.I.; Olsen, Y. Food selection and digestion characteristics of Atlantic halibut (Hippoglossus hippoglossus) larvae fed cultivated prey organisms. Aquaculture 2000, 181, 293-310. [CrossRef]

154. Meng, Y.; Wang, J.; Wang, Z.; Zhang, G.; Liu, L.; Huo, G.; Li, C. Lactobacillus plantarum KLDS1.0318 Ameliorates Impaired Intestinal Immunity and Metabolic Disorders in Cyclophosphamide-Treated Mice. Front. Microbiol. 2019, 10, 731. [CrossRef] [PubMed]

155. Doan, H.V.; Doolgindachbaporn, S.; Suksri, A.J.A.N. Effect of Lactobacillus plantarum and Jerusalem artichoke (Helianthus tuberosus) on growth performance, immunity and disease resistance of Pangasius catfish (Pangasius bocourti, Sauvage 1880). Aquac. Nutr. 2016, 22, 444-456. [CrossRef] 